\title{
Instabilities in Amorphous Oxide Semiconductor Thin-Film Transistors
}

\author{
John F. Conley, Jr., Senior Member, IEEE
}

(Invited Paper)

\begin{abstract}
Thin-film transistors (TFTs) fabricated using amorphous oxide semiconductors (AOS) exhibit good electron mobility (5 to $\left.>50 \mathrm{~cm}^{2} / \mathrm{V} \cdot \mathrm{s}\right)$, they are transparent, and they can be processed at low temperatures. These new materials show a great promise for high-performance large-area electronics applications such as flexible electronics, transparent electronics, and analog current drivers for organic light-emitting diode displays. Before any of these applications can be commercialized, however, a strong understanding of the stability and reliability of AOS TFTs is needed. The purpose of this paper is to provide a comprehensive review and summary of the recently emerging work on the stability and reliability of AOS TFTs with respect to illumination, bias stress, ambient effects, surface passivation, mechanical stress, and defects, as well as to point out areas for future work. An overview of the TFT operation and expected reliability concerns as well as a brief summary of the instabilities in the well-known $\mathrm{Si}_{3} \mathrm{~N}_{4} / a-\mathrm{Si}: \mathrm{H}$ system is also included.
\end{abstract}

Index Terms-Amorphous oxide semiconductors (AOS), bias stressing, reliability, stability, transparent thin-film transistors (TTFTs).

\section{INTRODUCTION}

A CTIVE matrix liquid crystal displays (AMLCDs) and other large-area electronics applications are currently dominated by thin-film transistors (TFTs) based on either amorphous or polycrystalline Si. Although hydrogenated amorphous $\mathrm{Si}(a-\mathrm{Si}: \mathrm{H})$ allows fabrication of TFT arrays at low temperature and low cost and has been well proven for large-area commercial applications, this technology is plagued by low electron mobility $\left(\sim 1 \mathrm{~cm}^{2} / \mathrm{V} \cdot \mathrm{s}\right)$ and well-known instabilities with respect to bias stressing [1] and light exposure [2]. Polycrystalline Si-based TFTs, on the other hand, can exhibit electron mobility in excess of $50 \mathrm{~cm}^{2} / \mathrm{V} \cdot \mathrm{s}$, but large-area applications have been proven to be difficult, and the relatively high thermal budget makes poly-Si unsuitable for flexible substrates. In addition, both of these materials are opaque, which is a disadvantage for display applications. Thus, the search has continued for higher

Manuscript received April 29, 2010; revised August 13, 2010; accepted August 14, 2010. Date of publication August 23, 2010; date of current version January 26, 2011. This work was supported in part by the National Science Foundation under Grant DMR-0805372, a Research Experience for Undergraduates supplement, and the Oregon Nanoscience and Microtechnologies Institute.

The author is with the School of Electrical Engineering and Computer Science, Oregon State University, Corvallis, OR 97333 USA (e-mail: jconley@eecs.orst.edu).

Color versions of one or more of the figures in this paper are available online at http://ieeexplore.ieee.org.

Digital Object Identifier 10.1109/TDMR.2010.2069561 mobility materials that allow for a stable device operation and that can be processed at low temperatures.

In 2003, several groups reported on transparent TFTs (TTFTs) based on $\mathrm{ZnO}$, which is a wide-bandgap semiconductor [3]-[5]. These original devices generated excitement not only because they were transparent but also because they exhibited electron mobilities $(\mu)$ of $0.3-2.5 \mathrm{~cm}^{2} / \mathrm{V} \cdot \mathrm{s}$, threshold voltages $\left(V_{T}\right)$ as low as $\sim 0-3 \mathrm{~V}$ [4], [5], and $I_{\mathrm{ON}} / I_{\mathrm{OFF}}$ ratios of $\sim 10^{7}$. Since this original $\mathrm{ZnO}$ work, a number of novel materials have been used to make TFTs and TTFTs, including $\mathrm{In}_{2} \mathrm{O}_{3}, \mathrm{SnO}_{2}, \mathrm{InGaZnO}$ (IGZO), $\mathrm{ZnSnO}$ (ZTO), ZnInO (ZIO), SnGaZnO (TGZO), InGaO (IGO), ZnInSnO (ZITO), and $\mathrm{ZnON}$. All of these materials are n-type due to the existence of intrinsic donors. Although $\mathrm{ZnO}, \mathrm{In}_{2} \mathrm{O}_{3}$, and $\mathrm{SnO}_{2}$ are typically polycrystalline in thin-film form, crystallization is frustrated in multicomponent materials such as IGZO, ZTO, ZIO, IGO, TGZO, and ZITO. These latter materials are referred to as amorphous oxide semiconductors (AOS).

This relatively new class of materials possesses several advantages for TFT applications [6], which include the following: 1) an amorphous crystal structure which, due to a lack of grain boundaries, can aid in achieving good uniformity and relatively easier manufacturing; 2) low-temperature processing, which is suitable for flexible substrates such as plastic or Mylar; 3) electron mobility in the range of 5 to $>50 \mathrm{~cm}^{2} / \mathrm{V} \cdot \mathrm{s}$, which is about ten times greater than $a-\mathrm{Si}: \mathrm{H}$; 4) low sensitivity to visible light; and 5) transparency in visible region.

A unique aspect of these AOS materials is that the electron mobility is not strongly sensitive to the crystal structure, as is the case for $\mathrm{Si}$ or other covalently bonded semiconductors. The low sensitivity of the AOS mobility to the crystal structure was explained by Nomura et al. [7] as arising from the nature of the chemical bonding in these $(n-1) \mathrm{d}^{10} \mathrm{~ns}^{0} \quad(n \geq 4)$ metal oxides. Carrier transport in covalently bonded materials such as $\mathrm{Si}$ is primarily through the directional $\mathrm{sp}^{3}$ orbitals so that introducing randomness into the structure greatly reduces bond overlap and carrier mobility. In $(n-1) \mathrm{d}^{10} \mathrm{~ns}^{0}(n \geq 4)$ metal oxides, the higher ionicity of the bonding leads to a conduction band based on nondirectional ns orbitals. Because the overlap of these s orbitals is not significantly altered by the introduction of randomness, carrier transport and, thus, mobility is relatively insensitive to randomness. Therefore, although the mobility of amorphous $\mathrm{Si}$ is more than two orders of magnitude less than that of polycrystalline $\mathrm{Si}$, the mobility of the AOS materials is only about two to five times less than their crystalline 
counterparts. This fundamental difference in bonding may also play a role in TFT stability and reliability [8], [9].

Although it will be extremely difficult to displace $a-\mathrm{Si}: \mathrm{H}$ in the mature AMLCD industry, AOS materials offer great promise for the upcoming and potential applications such as TFT backplanes for high-performance AMLCDs, 3-D displays, active matrix organic light-emitting diode (AMOLED) displays, flexible electronics, and transparent electronics [6], [10][14]. For example, it is thought that future high-end products, such as ultrahigh-resolution displays with frame rates greater than $120 \mathrm{~Hz}$ and sizes greater than $50 \mathrm{in}$, will require transistors with higher performance than $a-\mathrm{Si}: \mathrm{H}$ [10], [13], [14]. The AOS TFTs may also be a viable option for AMOLEDs. Because AMOLED displays are emissive and current driven, TFT stability is critical. Although mobility and threshold voltage $\left(V_{t}\right)$ stability are typically not vitally important for a switching transistor, the brightness of each pixel in an emissive AMOLED display is highly dependent on the drain current of the driving transistor [13]-[15]. TFTs must remain stable over time as any shift in $V_{T}$ would change the brightness of an individual pixel and would cause display nonuniformity [6], [13]-[18]. Although it is possible to use $a-\mathrm{Si}: \mathrm{H}$ for this application, its inherent instabilities must be compensated with additional TFTs, resulting in a substantial area penalty and a reduction in the "transparency" of the display [11].

Despite the importance of a stable operation for potential applications, there have been relatively few studies to date on the stability and reliability of the many new AOS TFTs. However, even though this work is still at an early stage, a number of potential reliability problems have been identified and have begun to be characterized in a number of systems. The purpose of this paper is to provide a comprehensive review and summary of the rapidly expanding work on instabilities in AOS TFTs and TTFTs caused by illumination, bias stress, ambient/surface interaction, simultaneous light exposure/bias stressing, and mechanical stress, as well as the impact of surface passivation and the current understanding of defects. Areas for future work are identified. A brief background discussion of TFT structure, TFT operation, and types of instabilities is included to aid the reader in interpreting this work. To help place this emerging AOS work in perspective, brief summaries of the well-known instabilities in the $\mathrm{Si}_{3} \mathrm{~N}_{4} / a-\mathrm{Si}: \mathrm{H}$ system are also included. Note that this review will focus on the stress-induced changes in performance rather than the overall electrical performance (see [6]), and thus, it will primarily include studies with stability and reliability results.

\section{TFT BACKGROUND}

To provide a basis for understanding and interpreting the recent work that is investigating the stability and reliability of new AOS TFTs and TTFTs, a brief discussion of TFT structure, operation, and potential instability problems is included in this section.

\section{A. TFT and TTFT Device Structure}

There are four major classes of TFT devices: 1) staggered top gate; 2) staggered bottom gate (SBG); 3) coplanar top gate;

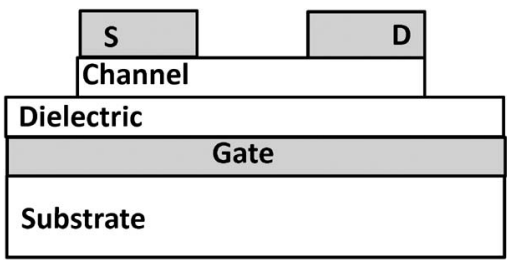

(a)

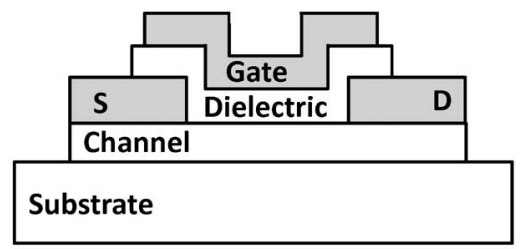

(b)

Fig. 1. Schematic cross section of the (a) SBG and (b) coplanar top gate TFTs.

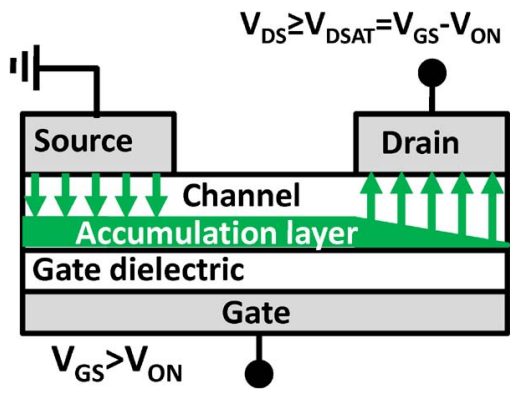

Fig. 2. Schematic cross section of an SBG TFT operating in accumulation (adapted from the study in [6]).

and 4) coplanar bottom gate [19]. For the AOS work published to date, the SBG structure dominates with only a few groups fabricating coplanar top gate devices. Shown in Fig. 1 are schematic cross sections of the (a) SBG and (b) coplanar top gate structures. In the SBG device structure [Fig. 1(a)], the gate electrode is deposited first, followed by the gate dielectric, the AOS channel, and finally the source and the drain. When we say staggered, it is meant that the source and the drain are not in the same plane as the conductive channel. The gate electrode can be either a blanket film or a patterned film. For TTFTs, the substrate is typically glass, and a transparent conductor such as ITO or $\mathrm{ZnO}: \mathrm{Al}$ is used for the source, gate, and drain.

\section{B. TFT Operation}

All of the new AOS materials listed in the introduction are intrinsically n-type. A major challenge for the oxide semiconductor technology has been the formation of p-type material [20]. Because only the n-type material is available, operation differs from that of the MOS technology in which the device is turned on by the formation of an inversion layer. For disordered wide-bandgap AOS TFTs, inversion is not practical, and devices must be operated in accumulation [6], [21]. As shown in Fig. 2, the AOS TFTs are turned on by applying a positive bias to the gate in order to form an accumulation layer in the AOS channel. As in a MOS device, pinchoff and saturation occur when $V_{\mathrm{DS}}>\left(V_{G}-V_{\mathrm{ON}}\right)$. Note that, in the SBG configuration shown, electron transport takes place from the source, across the thickness of the AOS layer to the 


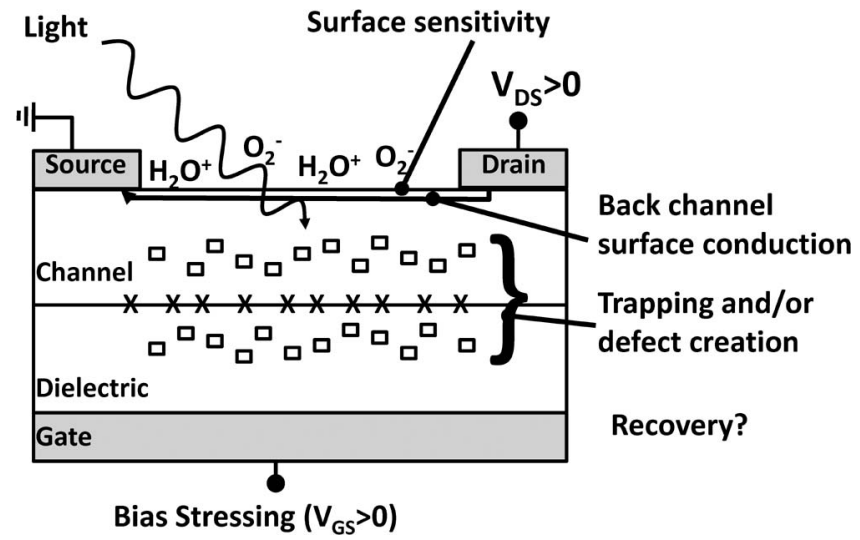

Fig. 3. Schematic summary of the potential instabilities in the AOS TFTs.

AOS/gate dielectric interface, along this interface, and then back across the thickness of the AOS layer to the drain. Note also that the carrier density in the AOS channel layer must be low (typically $10^{13}-10^{16} / \mathrm{cm}^{3}$ ) or the device functions as a voltage-controlled resistor rather than as a transistor. As AOS TFTs are being considered for macroelectronics applications, the majority of the reported devices are typically very large compared to MOSFETs, with lengths and widths typically in the range of $10 \mathrm{~s}$ to greater than $100 \mu \mathrm{m}$.

\section{Stability Concerns in the AOS TFTs}

Based on the understanding that has been developed for $a$-Si:H/ $/ \mathrm{Si}_{3} \mathrm{~N}_{4}$ TFTs [1], [2], [19], the following can be expected: 1) light exposure/illumination and 2) bias stressing may lead to instabilities such as charge trapping and, possibly, defect formation in the AOS, in the gate dielectric, or at the AOS/dielectric interface. It might also be expected that an increased temperature or a simultaneous exposure of a device to both bias stress and illumination could lead to enhanced or additional instabilities. In the SBG structure shown in Fig. 1(a), the AOS surface is exposed to ambient. Metal oxides are well known as gas sensors [22]-[25], and thus, one might also expect instabilities due to 3) AOS surface/ambient interaction. While not an issue for top-gate configurations, the interaction with ambient molecules on the AOS surface could lead to "back-channel" surface conduction in the bottom gate devices. The encapsulation or passivation of the AOS surface, so as to reduce or eliminate the interaction with the ambient, would be expected to have an impact on the operation and stability of bottom gate devices. Finally, the generation and recovery of all of these instabilities over time may lead to a time-dependent operation. The stability concerns are shown in Fig. 3.

\section{ReVIEW OF The AOS TFT Stability Studies}

In this section, recently emerging work concerning the stability of TFTs made from a variety of AOS materials in various device configurations will be reviewed. In particular, illumination, bias stressing, and surface-related instabilities will be discussed. The interactions between these (such as simultaneous illumination/bias stressing) as well as the impact of passivation will also be discussed. To help put these results in context, brief summaries of the response of the $a$-Si:H TFT technology are included.

\section{A. Illumination}

In a commercial AMLCD, switching TFTs are continuously exposed to illumination from the backlight [10]. Thus, for AMLCD as well as transparent applications, TTFTs should be insensitive to visible light. Staebler and Wronski [2] were the first to demonstrate that $a-\mathrm{Si}: \mathrm{H}$ suffers degradation under illumination (the well-known Staebler-Wronski Effect). For example, efficiency of $a-\mathrm{Si}: \mathrm{H}$ solar cells is reduced after initial exposure to light. They reported a permanent increase in defect density during illumination, which was reversible, but required annealing at $\sim 180{ }^{\circ} \mathrm{C}-200{ }^{\circ} \mathrm{C}$. Note that, although wide-bandgap devices might be expected to be unaffected by subbandgap illumination, the presence of bandtail states in these amorphous materials can lead to bandgap narrowing and absorption at longer wavelengths [21], [26]. This section discusses recent reports of the impact of various wavelength illumination on a variety of unbiased and unpassivated TFTs.

Gorrn et al. [27] looked at 628-425-nm illumination of unencapsulated SBG ZTO TFTs with 220-nm ATO gate dielectrics. ATO is an aluminum oxide/titanium oxide laminate deposited via atomic layer deposition (ALD) at $350{ }^{\circ} \mathrm{C}$. A 60 -nm ZTO channel with a Zn-to-Sn composition ratio of 36:64 was then deposited via plasma assisted pulsed laser deposition (PA-PLD) at $450{ }^{\circ} \mathrm{C}$. They reported a little change as a result of the $628-\mathrm{nm}$ illumination. Illumination at 425,470 , and $525 \mathrm{~nm}$, however, resulted in a decrease in $V_{T}$ and $\mu_{\text {sat }}$ and an increase in $I_{\mathrm{ON}} / I_{\mathrm{OFF}}$, with the parameter shift occurring over a period of hours. A shorter $\lambda$ and a higher intensity resulted in greater parametric shifts. The magnitude of these shifts was strongly dependent on the ZTO deposition temperature. The samples deposited at $250{ }^{\circ} \mathrm{C}$ showed a $20 \%$ decrease in $\mu_{\text {sat }}$, while the samples deposited at $350{ }^{\circ} \mathrm{C}$ and above showed less than $20 \%$ shift. All light-induced changes were found to be fully reversible, and they recovered to the initial values when the light was turned off. Persistent photoconductivity was observed with an $\sim 20$-h time constant. They concluded that the time constant of the recovery was not governed by the dielectric, but they suggested that the persistent photoconductivity may be due to temporary trapping or, since these devices were unpassivated, oxygen readsorption at the surface. Shown in Fig. 4 is a plot of $V_{T}$ and the saturation mobility $\left(\mu_{\mathrm{SAT}}\right)$ versus time during and after exposure to a 425 -nm light. During illumination, $V_{T}$ shifts negatively, and $\mu_{\mathrm{SAT}}$ is reduced. After the exposure ends, both $V_{T}$ and $\mu_{\mathrm{SAT}}$ recover over a period of many hours. They later determined that chemisorption of oxygen is critical concern for stability [70].

Paine et al. [28] examined unpassivated SBG IZO TTFTs, with the $\mathrm{SiO}_{x}$ gate dielectric deposited via plasma-enhanced chemical vapor deposition (PECVD) at $280{ }^{\circ} \mathrm{C}$ and with the IZO channel dc sputtered at room temperature. Similar to the study in [27], they found out that, while ambient fluorescent light exposure produced little effect, devices exposed to UV illumination showed the time-dependent increase in conductivity and decrease in $I_{\mathrm{ON}} / I_{\mathrm{OFF}}$. The full recovery of the persistent photoconductivity occurred over a period of $24 \mathrm{~h}$. 


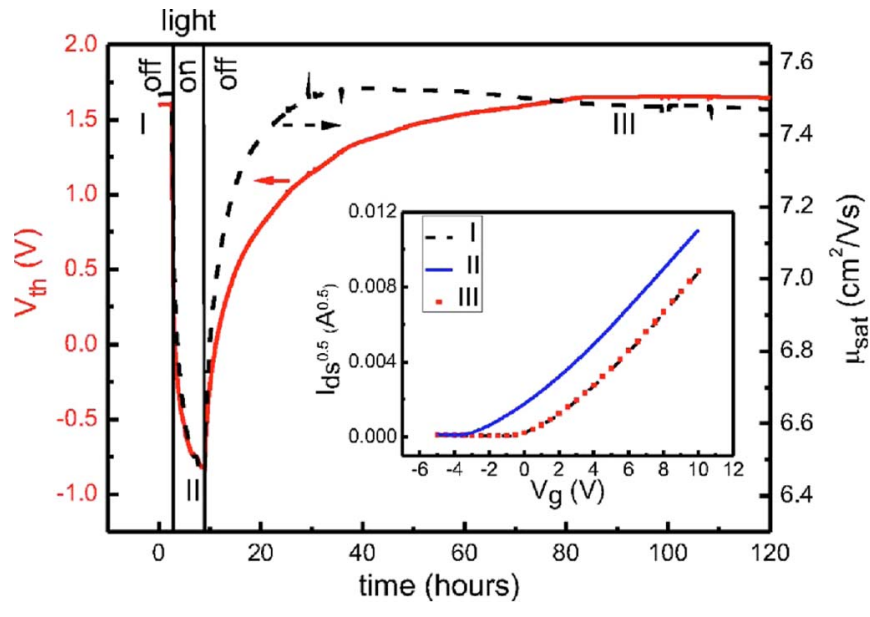

Fig. 4. Data from the study in [27]. Plot of (solid red) $V_{T}$ and (dashed black) $\mu_{\text {sat }}$ versus time during and after a 425 -nm illumination. The inset shows the $I_{D}$ versus $V_{G}$ transfer curves. I-(Dashed black) Preillumination. II-(Solid blue) During illumination. III-(Dotted red) After full recovery.

Barquinha et al. [29] also reported similar results for unpassivated SBG IZO TTFTs, with the 220-nm ATO gate dielectric deposited via ALD at $350{ }^{\circ} \mathrm{C}$ and with the 80 -nm IZO channel deposited via room temperature RF sputtering. Visible to UV illumination produced a decrease in $I_{\mathrm{ON}} / I_{\mathrm{OFF}}$ and mobility, a negative shift of $V_{\mathrm{ON}}$, and an increase in hysteresis.

In summary, it has generally been reported that, for unbiased devices, longer wavelength ambient lighting, well below the bandgap, has little effect [27]-[29]. For shorter wavelength exposures approaching the bandgap, $V_{\mathrm{ON}}$ shifts negatively, $\Delta V_{\mathrm{HYS}}$ increases, $I_{\mathrm{ON}} / I_{\mathrm{OFF}}$ decreases, mobility $(\mu)$ decreases, and subthreshold swing $(S)$ increases as $\lambda$ decreases. Higher intensity light and longer exposure times typically result in a greater parametric shift. In contrast to $a-\mathrm{Si}: \mathrm{H}$, all of these effects appear to be reversible when left in the dark at room temperature. Note that it is likely that at least some of the illumination-induced effects that have been reported could be attributed to the interaction of the light with the ambient gas molecules on the unpassivated AOS channel surface rather than to the direct interaction of the light with the AOS material (see Section III-C). Note that wavelengths below $430 \mathrm{~nm}$ may be filtered without compromising display performance [27]. The effect of illumination during bias stressing is discussed in the following section.

\section{B. Bias Stressing}

Bias stressing of $a-\mathrm{Si}: \mathrm{H} / \mathrm{Si}_{3} \mathrm{~N}_{4}$ TFTs results in the following two primary instability mechanisms [1], [19]: 1) defect creation in the channel and 2) trapping in the gate dielectric or at the dielectric/channel interface. Although these effects can be recovered by elevated temperature annealing, they are irreversible without annealing.

Very recently, a number of gate bias and combined gate/drain bias (bias-current) stressing studies have been conducted on various AOS/dielectric TFT combinations. These studies will be subdivided into low-field positive gate bias stressing, highfield positive gate bias stressing, negative gate bias stressing, dynamic bias stressing, bias stressing under illumination, and

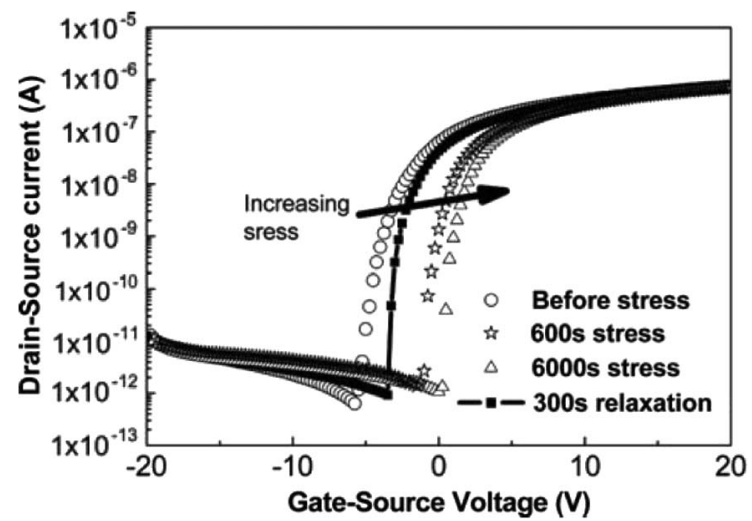

Fig. 5. Data from the study in [31]. Transfer characteristics for an SBG $\mathrm{In}_{2} \mathrm{O}_{3}$ TFT, with the 200-nm PECVD $\mathrm{SiO}_{x}$ gate dielectric and the 100-nm $\mathrm{In}_{2} \mathrm{O}_{3}$ channel deposited via reactive ion beam assisted evaporation, measured (circles) before stress, (stars) after a 600-s stress (with $V_{G}=V_{\mathrm{DS}}=+10 \mathrm{~V}$ ), (triangles) after a 6000-s stress, and (solid) after a 300-s relaxation.

process dependence. For AMLCD applications, the transistor is not always on, and recovery when unbiased must be considered as well. This section will conclude with a discussion on modeling and potential mechanisms. Note that the focus will be on qualitative response. Due to differences in channel dimensions, stress conditions, device structure, passivation, etc., it is not simple to compare precisely quantitative responses to stressing.

1) Low-Field Positive Gate Bias Stressing: Many groups have investigated the impact of low-field $(\lesssim 1 \mathrm{MV} / \mathrm{cm})$ positive bias stressing on a variety of different material systems [30][50]. The AOS materials investigated include $\mathrm{ZnO}, \mathrm{ZTO}$, and $\mathrm{In}_{2} \mathrm{O}_{3}$, with the majority of the work being performed on IGZO. The dielectric materials include $\mathrm{SiO}_{2}, \mathrm{Al}_{2} \mathrm{O}_{3}$, ATO, and $\mathrm{SiN}_{x}$. Unless otherwise noted, devices may be assumed to be without surface passivation. As discussed in Section III-D and E, ambient and surface passivation can have a large impact on bias stressing. The devices discussed in this section may be assumed to have been stressed in air, at room temperature, and in the dark, unless otherwise indicated. Bias stressing during illumination is also discussed in the following discussion.

The first bias stressing study of oxide semiconductor TFTs was performed by Cross and DeSouza on SBG ZnO TFTs consisting of an RF-magnetron-sputtered 100-nm ZnO channel on a 150-nm thermally grown $\mathrm{SiO}_{2}$ gate dielectric [30]. In this paper, they reported that stressing for up to $10^{4} \mathrm{~s}$ at a $V_{G}$ of up to $+30 \mathrm{~V}$ produced a positive parallel $V_{T}$ (or $V_{\mathrm{ON}}$ ) shift, with little or no change in $S$ or $\mu$. A rapid recovery was observed without annealing or bias. Similar results have been reported in a variety of other SBG TFT and TTFT systems. Representative low-field stressing results from Vygraneko et al. [31] are shown in Fig. 5.

Other material systems in which a similar response to lowfield stressing was reported include a $100-\mathrm{nm}$ thermal $\mathrm{SiO}_{2}$ gate dielectric/40-nm RF-sputtered amorphous IGZO channel SBG TFTs stressed with $V_{G}=+15 \mathrm{~V}$ for up to $10^{5} \mathrm{~s}$ [32], a $90-\mathrm{nm}$ PECVD $\mathrm{SiO}_{x}$ gate dielectric/50-nm RF-sputtered amorphous IGZO channel SBG TFTs stressed at $V_{G}=+6 \mathrm{~V}$ for $500 \mathrm{~h}$ [33], a 400-nm PECVD $\mathrm{SiN}_{x}$ gate dielectric/70-nm RFsputtered amorphous IGZO (with $\mathrm{SiO}_{x}$ top surface passivation) 


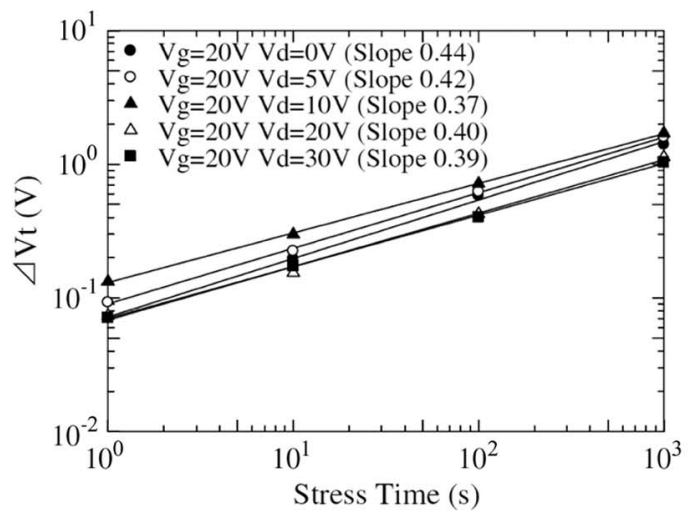

(a)

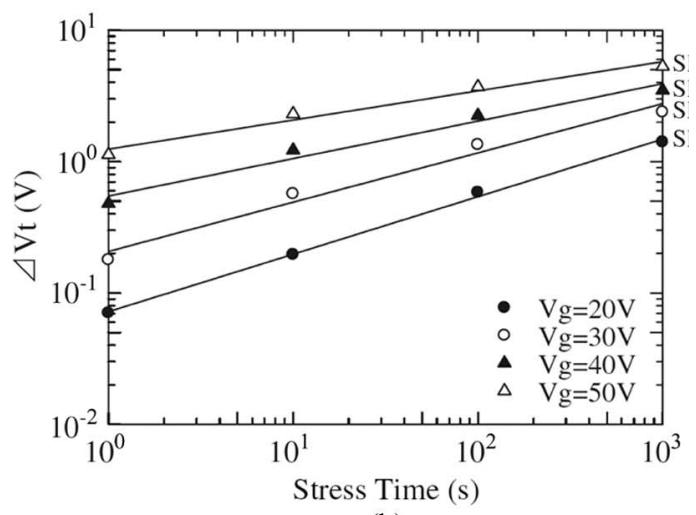

(b)

Fig. 6. Data from the study in [34]. $\Delta V_{t}$ versus stress time for a $400-\mathrm{nm}$ PECVD SiN $x / 70$-nm RF-sputtered IGZO SBG TFTs with $\mathrm{SiO}_{x}$ top surface passivation (a) for various $V_{G} / V_{\mathrm{DS}}$ combinations and (b) as a function of the $V_{G}$ stress voltage.

SBG TFTs stressed at a $V_{G}$ of up to $+50 \mathrm{~V}$ [34], a $120-\mathrm{nm}$ thermally grown $\mathrm{SiO}_{2} / 20$-nm spin coated ZTO channel SBG TFTs stressed at $V_{G}=+20 \mathrm{~V}$ for $3600 \mathrm{~s}$ [35], a 220-nm ALD ATO gate dielectric/60-nm PA-PLD amorphous ZTO $(36 \%$ $\mathrm{Zn} / 64 \% \mathrm{Sn}$ ) channel SBG TTFTs stressed at $V_{G}=+10 \mathrm{~V}$ for up to $10^{5}$ s [36], a 200-nm PECVD $\mathrm{SiO}_{x}$ gate dielectric/100-nm reactive ion beam assisted evaporation $\mathrm{In}_{2} \mathrm{O}_{3}$ channel stressed at $V_{G}=+10 \mathrm{~V}$ for up to $6000 \mathrm{~s}$ [37], and a 300-nm $\mathrm{Si}_{3} \mathrm{~N}_{4}$ gate dielectric/50-nm RF-magnetron-sputtered IZO coplanar bottom gate TFTs stressed at $V_{G}=+30 \mathrm{~V}$ for up to $1.2 \times 10^{4} \mathrm{~s}$ [38].

As shown in Fig. 6, Fujii et al. [34] investigated low-field bias-current stressing with $\mathrm{V}_{G}=+20 \mathrm{~V}$ and a $V_{\mathrm{DS}}$ of up to $+30 \mathrm{~V}$ and showed that the overall degradation mode was not changed by increasing $V_{\mathrm{DS}}$. They still observed recoverable positive $V_{T}$ shift, accompanied by little degradation of $S$ and $\mu$.

Other groups have also reported similar results to Fujii et al. for a combined positive-bias-current stressing $\left(V_{G}>0 ; V_{\mathrm{DS}}>\right.$ $0 \mathrm{~V}$ ) of various gate dielectric/AOS channel stacks, including a 220-nm ALD ATO gate dielectric/PLD amorphous IGZO SBG TTFTs stressed at $V_{G}=+30 \mathrm{~V}$ and $V_{\mathrm{DS}}=+1 \mathrm{~V}$ [39]; a 150-nm thermal $\mathrm{SiO}_{2} / 40$-nm PLD amorphous IGZO channel SBG TFTs stressed at a constant current of $I_{D}=5 \mu \mathrm{A}$, with $V_{G}=V_{\mathrm{DS}}$, for $50 \mathrm{~h}$ [40]; a 100 -nm thermal $\mathrm{SiO}_{2} / 50$-nm RFsputtered amorphous IGZO channel SBG TFTs stressed at $V_{G}=V_{\mathrm{DS}}=+30 \mathrm{~V}$ for up to $10^{5} \mathrm{~s}$ [41]; a 220-nm ALD ATO/60-nm PA-PLD ZTO (36\% Zn/64\% Sn) SBG TTFTs stressed at $V_{G}=V_{\mathrm{DS}}=+10 \mathrm{~V}$, with $I_{D}=188 \mu \mathrm{A}$ [35], [42]; a 200-nm ALD $\mathrm{Al}_{2} \mathrm{O}_{3} /$ RF-sputtered ZTO channel SBG TFTs stressed with $V_{G}=20 \mathrm{~V}$ and $V_{\mathrm{DS}}=1 \mathrm{~V}$ [43]; a 200-nm RF-sputtered $\mathrm{Al}_{2} \mathrm{O}_{3}$ gate dielectric/60-nm RF-sputtered $\mathrm{ZnO}$ channel SBG TFTs stressed at $V_{G}=V_{\mathrm{DS}}=+7 \mathrm{~V}$ [44]; a 100-nm thermal $\mathrm{SiO}_{2}$ gate dielectric/40-nm RF-sputtered IGZO channel SBG TFTs stressed at $V_{G}=+10 \mathrm{~V}$ and $V_{\mathrm{DS}}=+0.5 \mathrm{~V}$ [18]; and 50-nm ZIO SBG TFTs with either 200-nm PECVD $\mathrm{SiO}_{x}$ or 200-nm PECVD $\mathrm{SiN}_{x}$ gate dielectrics stressed at $V_{G}=+20 \mathrm{~V}$ and $V_{\mathrm{DS}}=+0.1 \mathrm{~V}$ [45]. Lee et al. [46] reported a similar response for organic photoacryl passivated IGZO SBG TFTs on flexible polyimide films with either 200-nm PECVD $\mathrm{SiO}_{x}$ or 200-nm PECVD $\mathrm{SiN}_{x}$ gate dielectrics stressed at $V_{G}=+15 \mathrm{~V}$ and $V_{\mathrm{DS}}=+5.1 \mathrm{~V}$, with the $\mathrm{SiO}_{x}$ gate dielectric devices exhibiting a reduced shift, possibly due to a reduced $\mathrm{H}$ content. In addition, the 200-nm PECVD $\mathrm{SiO}_{x}$ gate dielectric/amorphous IGZO channel coplanar homojunction bottom gate TFTs, with the PECVD $\mathrm{SiO}_{x} / \mathrm{Si}_{3} \mathrm{~N}_{4}(50 / 300 \mathrm{~nm})$ surface passivation stressed at $V_{G}=$ $V_{\mathrm{DS}}=+12 \mathrm{~V}$ and $I_{D}=4 \mu \mathrm{A}$ at $60{ }^{\circ} \mathrm{C}$ for $10^{5} \mathrm{~s}$, showed a small parallel positive $V_{T}$ shift [47]. Zhao et al. [48] looked at the $50-\mathrm{nm} \mathrm{Al}_{2} \mathrm{O}_{3}$ gate dielectric/30-nm $\mathrm{ZnO}$ channel SBG TFTs that were surface passivated with a 30-nm layer of ALD $\mathrm{Al}_{2} \mathrm{O}_{3} . \mathrm{Al}_{2} \mathrm{O}_{3}$ gate dielectric and $\mathrm{ZnO}$ were deposited via a novel plasma-enhanced ALD process using either DEZ/ $\mathrm{N}_{2} \mathrm{O}$ or TMA/ $\mathrm{CO}_{2}$ as precursors. Low-field stressing at $V_{G}=V_{D}=$ $+3 \mathrm{~V}$ for $40000 \mathrm{~s}$ resulted in a very small $(<50 \mathrm{mV}) V_{T}$ shift. Similar results were reported by Mourey et al. [49].

Although the vast majority of the groups have reported that a low-field positive bias stress results in a positive $V_{T}$ shift, with little or no change in $S$ or $\mu$, there have been exceptions. Flewitt et al. [50] reported an increase in mobility in stressed thermal $\mathrm{SiO}_{2}$ /sputtered IZO SBG TFTs, which they attributed to a reduced trapping/detrapping in the IZO channel due to an increased occupancy of defects near the IZO conduction band under a positive gate bias. Although their similar devices with either PECVD $\mathrm{SiO}_{x}$ or $\mathrm{SiN}_{x}$ gate dielectrics exhibited a typical behavior (discussed earlier), Hoffman et al. [45] reported that the 50-nm ZIO channel SBG TFTs, with the $\mathrm{HfO}_{2}$ gate dielectrics deposited by either ALD or sputtering, exhibited a complex response to low-field positive bias stressing. An initial positive $V_{T}$ shift at short stress times was followed by a turnaround and increasing negative $V_{T}$ shifts at longer stress times, which they did not attempt to explain.

To summarize, based on the observations of a rigid positive shift of $V_{T}$ or $V_{\mathrm{ON}}$, which is accompanied by little or no change in $S$ or $\mu$ that is fully recoverable at room temperature, it has been generally concluded that electron trapping at or near the interface without the creation of new defects is the primary mechanism responsible for low-field stress-induced instabilities in AOS TFT devices.

Differences in the low-field bias stress response may be attributed to many things, including not only the details of the specific dielectric/channel interface [45], [46], [51], deposition methods, and postdeposition annealing but also bias-enhanced interaction between the ambient and the AOS surface in unpassivated devices. It is likely that in many of the early studies of unpassivated devices, the uncontrolled interaction with the ambient may have played a role in or may have even dominated the observed response (see Section III-C-E). 
2) High-Field Positive Gate Bias Stressing: The reports on accelerated positive bias stressing of AOS TFTs at fields higher than $1 \mathrm{MV} / \mathrm{cm}$ are not as consistent as the reports on lowfield stressing $(\lesssim 1 \mathrm{MV} / \mathrm{cm})$. Again, unless otherwise noted, the devices are assumed to be stressed at room temperature in the dark without surface passivation.

Several groups have reported that high-field positive bias stressing $(>1 \mathrm{MV} / \mathrm{cm})$ is similar to low-field stressing $\left(\lesssim 1 \mathrm{MV} / \mathrm{cm}\right.$ ), with larger positive $V_{T}$ shifts as the stress voltage is increased and with little or no change in $S, \mu$, or $I_{\mathrm{ON}} / I_{\mathrm{OFF}}$ [39], [52], [53]. For example, Lim et al. [53] looked at 96-nm ALD $\mathrm{Al}_{2} \mathrm{O}_{3}$ gate dielectric/66-nm ZnO:N channel SBG TFTs in which the $\mathrm{ZnO}: \mathrm{N}$ channel was deposited by a novel ALD process using DEZ/ $/ \mathrm{NH}_{4} \mathrm{OH}$ in $\mathrm{H}_{2} \mathrm{O}$ as precursors. Positive bias stressing at $V_{G}=+15 \mathrm{~V}$ and $V_{\mathrm{DS}}=+1 \mathrm{~V}$ induced positive $V_{T}$ shifts, with little change in $S$.

In other cases, high-field stressing ( $\gtrsim 1 \mathrm{MV} / \mathrm{cm}$ ) has been reported to lead to a recoverable $S$ and/or $\mu$ degradation. In the first study of bias stressing of the unpassivated ZnO SBG TFTs, Cross and Desouza [30], [54] reported an increased $S$ in thermal $\mathrm{SiO}_{2}$ gate dielectric/RF-sputtered $\mathrm{ZnO}$ channel $\mathrm{SBG}$ TFTs stressed at $V_{G} \simeq+3 \mathrm{MV} / \mathrm{cm}$. In one of the few studies involving top gate devices, Lee et al. [55] saw that $S$ degradation as result of $\sim+3-\mathrm{MV} / \mathrm{cm}$ bias stress was worse when 5-nm PECVD $\mathrm{SiN}_{x}$ interfacial layer was inserted between the 185-nm ALD $\mathrm{Al}_{2} \mathrm{O}_{3}$ gate and the RF-sputtered IGZO channel layer. Both of these groups implicated trap creation at the interface.

Fung et al. [56] subjected the 100-nm RF-sputtered $\mathrm{SiO}_{2} /$ 30-nm RF-sputtered IGZO channel SBG TFTs with sputtered $\mathrm{SiO}_{2}$ channel encapsulation to an elevated temperature (40$80{ }^{\circ} \mathrm{C}$ ) stress at $V_{G}=+14-20 \mathrm{~V}$ and $V_{\mathrm{DS}}=0 \mathrm{~V}$ for up to $10^{4} \mathrm{~s}$ and found a small fairly rigid positive $V_{T}$ shift, with a slight increase in $S$ and decrease in $\mu$. Although they saw little recovery at room temperature, complete recovery was observed after a $2-\mathrm{h} 200-{ }^{\circ} \mathrm{C}$ anneal in air. They implicated carrier injection from the channel and subsequent charge trapping with little creation of new defects.

Overall, there are not as clear general trends for accelerated positive bias stressing at fields $>1 \mathrm{MV} / \mathrm{cm}$ as there are for lower fields $(\lesssim 1 \mathrm{MV} / \mathrm{cm})$. In addition to the degradation that is consistent with that widely reported at low fields (recoverable positive $V_{T}$ shifts with no degradation of $S$ and $\mu$ and charge trapping without defect creation), there are also reports on changes in $S$ and $\mu, V_{T}$ shifts that require annealing, and defect creation. Besides material and processing differences, a likely explanation for the reduced agreement among highfield stressing studies is that surface/ambient interactions (see Section III-C-E) in unpassivated devices become even more important at higher fields.

3) Negative Gate Bias Stressing: n-type AOS TFTs operate in accumulation mode and require a positive gate bias to turn on. However, according to the study in [10], the amount of time that a typical TFT spends under a negative gate bias in AMLCD applications is approximately $500 \times$ the amount of time spent under a positive gate bias. Negative bias stress is therefore arguably as important or even more important than positive bias stress.

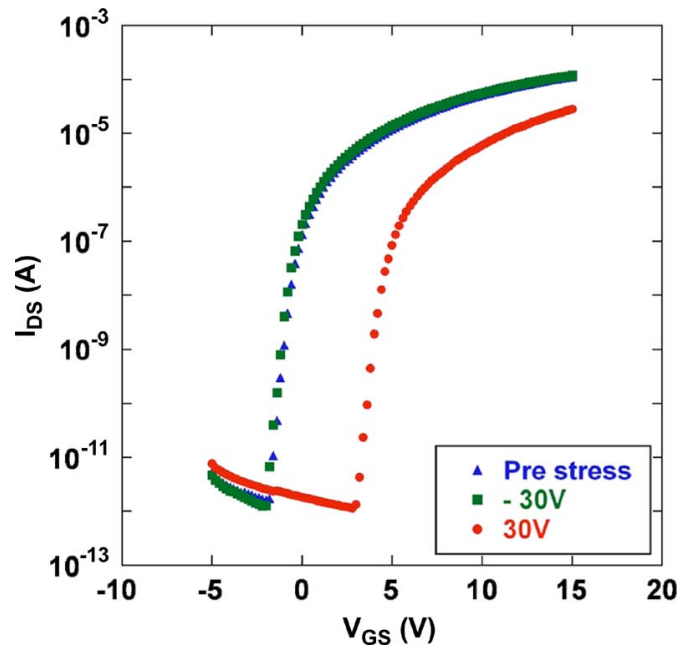

Fig. 7. Data from the study in [39]. Plot of $I_{D}$ versus $V_{G}$ for the 220-nm ATO/IGZO TTFTs stressed for $500 \mathrm{~s}$ under positive and negative gate biases, with $V_{\mathrm{DS}}=1 \mathrm{~V}$.

Negative gate bias stressing is often reported to result in negligible changes in $V_{T}, S$, and $\mu$ when the devices are stressed in the dark (Unless otherwise noted, the devices are assumed to be stressed at room temperature and without surface passivation.). For example, as shown in Fig. 7, Suresh et al. [39] saw negligible changes in 220-nm ALD ATO gate dielectric/pulse laser deposited (PLD) IGZO channel SBG TTFTs stressed under a negative bias. Similar results were reported in other systems, including thermal $\mathrm{SiO}_{2} / \mathrm{RF}$-sputtered IGZO SBG TFTs [32], thermal $\mathrm{SiO}_{2} /$ spin coated ZTO SBG TFTs [35], and unilluminated PE-ALD $\mathrm{Al}_{2} \mathrm{O}_{3}$ dielectric/PE-ALD ZnO SBG TTFTs [57].

In other cases, negative bias stressing has been reported to result in degradation. Cross and DeSouza [54] reported a recoverable negative $V_{T}$ shift in thermal $\mathrm{SiO}_{2} / \mathrm{RF}$-sputtered $\mathrm{ZnO}$ TFTs but concluded that their devices were "inherently unstable."

Gornn et al. [27] reported a negative $V_{T}$ shift, with $S$ degradation for ALD ATO dielectric/ZTO SBG TFTs but only for some compositions of ZTO. Liu et al. [38] subjected 300-nm $\mathrm{Si}_{3} \mathrm{~N}_{4}$ gate dielectric/50-nm RF-magnetron-sputtered IZO coplanar bottom gate TFTs to $V_{G}=-30 \mathrm{~V}$ for up to $1.2 \times 10^{4} \mathrm{~s}$ and saw negative $V_{T}$ shifts, with little or no change in $S$ and mobility. A nearly complete recovery was observed after $15 \mathrm{~h}$ at room temperature. Negative $V_{T}$ shifts were also seen in PECVD $\mathrm{SiO}_{x}$ passivated IGZO SBG TFTs, with the 200-nm PECVD $\mathrm{SiO}_{x}$ gate dielectrics stressed at $V_{G}=-30 \mathrm{~V}$ and $V_{D}=10.1 \mathrm{~V}$ [12].

Lee et al. [10] subjected $\mathrm{SiN}_{x}$ dielectric/IGZO SBG TFTs to negative bias current stressing with $V_{G}=-20 \mathrm{~V}$ and $V_{\mathrm{DS}}=$ $+10 \mathrm{~V}$ at $60^{\circ} \mathrm{C}$ while under illumination from a halogen lamp. As shown in Fig. 8, they reported a rigid negative shift, with insignificant changes in $S$ and $\mu_{\mathrm{FE}}$. They observed similar results in the dark, but with a smaller magnitude of the $V_{T}$ shift (Further discussion of bias stress under illumination appears in a following subsection.)

Seo et al. [58] subjected 200-nm PECVD $\operatorname{SiN}_{x} / 60-\mathrm{nm}$ $a$-IGZO channel SBG TFTs with and without $\mathrm{TiO}_{x}$ encapsulation to $V_{G}=-20 \mathrm{~V}$ and $V_{\mathrm{DS}}=0.1 \mathrm{~V}$ for $3000 \mathrm{~s}$ 


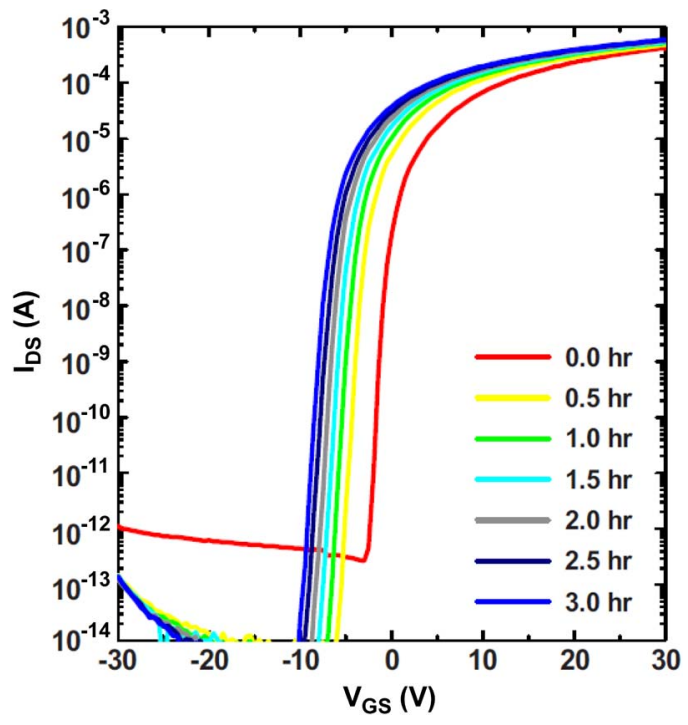

Fig. 8. Data from the study in [10]. Plot of $I_{D}$ versus $V_{G}$ as a function of time for the $\mathrm{SiN}_{x}$ dielectric/IGZO SBG TFTs exposed to a negative gate bias stress while under illumination.

at $60{ }^{\circ} \mathrm{C}$ and saw a rigid negative $V_{T}$ shift, with no change in $S$ and $\mu$.

Fung et al. [56] subjected 100-nm RF-sputtered $\mathrm{SiO}_{2} /$ 30-nm RF-sputtered IGZO channel SBG TFTs with sputtered $\mathrm{SiO}_{2}$ encapsulation to an elevated temperature $\left(40-80{ }^{\circ} \mathrm{C}\right)$ stress at $V_{G}=-12--20 \mathrm{~V}$ and $V_{\mathrm{DS}}=0 \mathrm{~V}$ for up to $10^{4} \mathrm{~s}$ and found a small fairly rigid negative $V_{T}$ shift, with a slight increase in $S$ and $\mu$. Although they saw a little recovery at room temperature, complete recovery was observed after a 2-h $200-{ }^{\circ} \mathrm{C}$ anneal in air. Lee et al., Seo et al., and Fung et al. all attributed the negative bias stress response to charge trapping at existing defects rather than to defect creation.

Finally, a positive $V_{T}$ shift without recovery was reported in the 200-nm PECVD $\mathrm{SiO}_{x} /$ reactive ion beam assisted 30-nm $\mathrm{In}_{2} \mathrm{O}_{3}$ SBG TFTs stressed at $V_{G}=-30 \mathrm{~V}$ [37].

In summary, the investigations of negative bias stressing appear to be divided between the following reports: 1) little effect and 2) negative $V_{T}$ shift, with little degradation of $S$ and $\mu$. Besides material differences, recent reports stating that both illumination [57] and humidity [10] exacerbate the effects of negative bias stress may provide a partial explanation for the varying observations. Processing and encapsulation have also been shown to have an impact on negative bias stressing [27], [58]. These interactions are discussed further in the following sections.

4) Dynamic Stressing: It is known that static stress may be pessimistic for many applications [59] and therefore it is useful to assess device stability under dynamic stressing as well as static stressing. So far, the only study of the frequency dependence of the dynamic bias stressing of AOS TFTs was performed by Cho et al. [52] who subjected 100-nm thermal $\mathrm{SiO}_{2}$ gate/40-nm RF-sputtered IGZO SBG TFTs to alternating cycles of stress $\left(V_{G}=+15 \mathrm{~V}\right.$ and $\left.V_{\mathrm{DS}}=0 \mathrm{~V}\right)$ and relaxation $\left(V_{G}=0 \mathrm{~V}\right.$ and $\left.V_{\mathrm{DS}}=+15 \mathrm{~V}\right)$. They found out that a positive gate bias dynamic stress results in positive $V_{T}$ shifts with no $S$ degradation that do not completely recover at room temperature. As shown in Fig. 9, they found out that

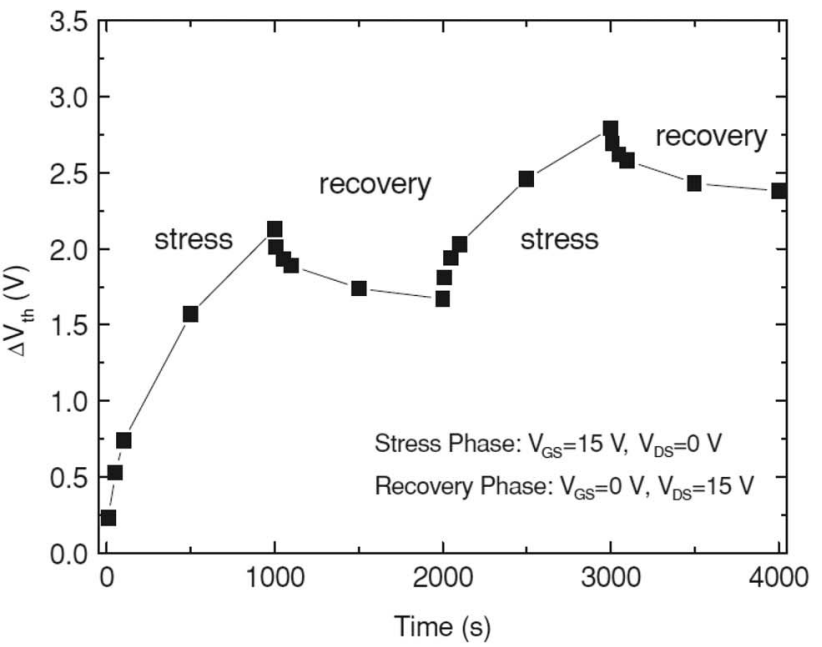

(a)

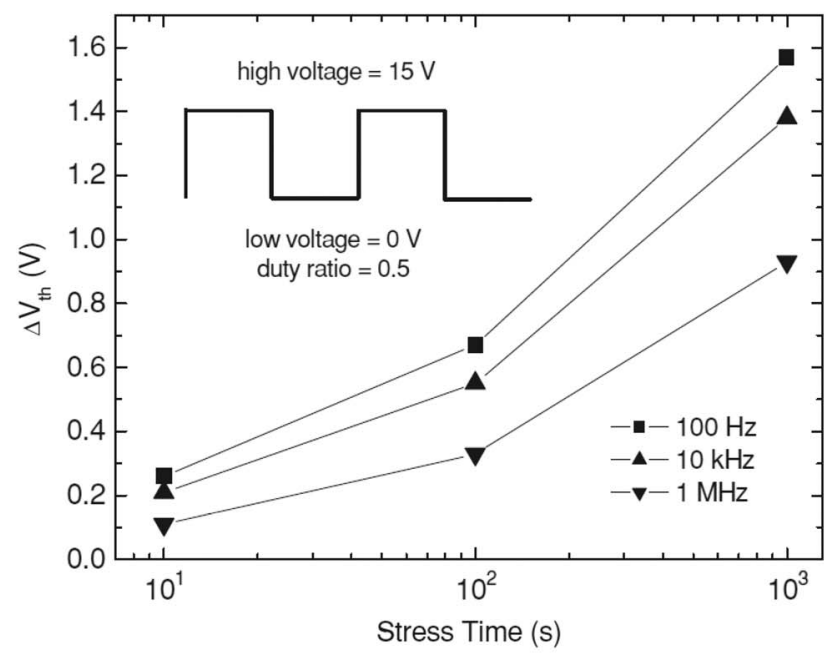

(b)

Fig. 9. Data from the study in [52]. Plot of $\Delta V_{T}$ versus time for 100-nm thermal $\mathrm{SiO}_{2}$ gate/40-nm RF-sputtered IGZO channel SBG TFTs subjected to (a) alternating stress and recovery and (b) dynamic stress at several different frequencies.

higher frequency stressing results in less damage. The work of Cho et al. [52] emphasizes the need to understand both timedependent stress and recovery effects with respect to the intended application.

5) Bias Stressing Under Simultaneous Illumination: In commercial AMLCD devices, switching TFTs are continuously exposed to illumination from the backlight [10]. Therefore, it is necessary not only to look separately at the impact of illumination and bias stressing on device operation but also to understand the impact of bias stressing while under continuous illumination. So far, it has been reported that illumination during bias stressing leads to an enhanced degradation.

Shin et al. [57] were the first to look at the impact of illumination on bias stressing. As shown in Fig. 10, for PE-ALD $\mathrm{Al}_{2} \mathrm{O}_{3} /$ PE-ALD ZnO TFTs, they found out that a 524-nm illumination exacerbates the $V_{T}$ shift for negative gate bias stressing but does not seem to impact positive gate bias stressing. Similar results were reported by Lee et al. [10] for $\mathrm{SiN}_{x}$ dielectric/IGZO SBG TFTs subjected to halogen lamp 


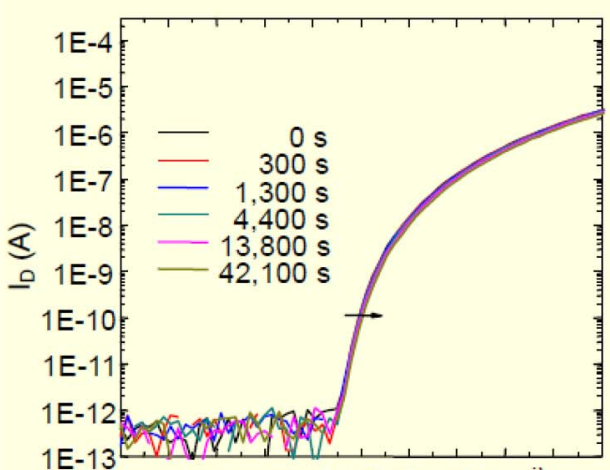

(a) $V_{G_{-} S T}=10 \mathrm{~V}, P_{\mathrm{ill}}=0 \mathrm{~mW} / \mathrm{cm}^{2}$

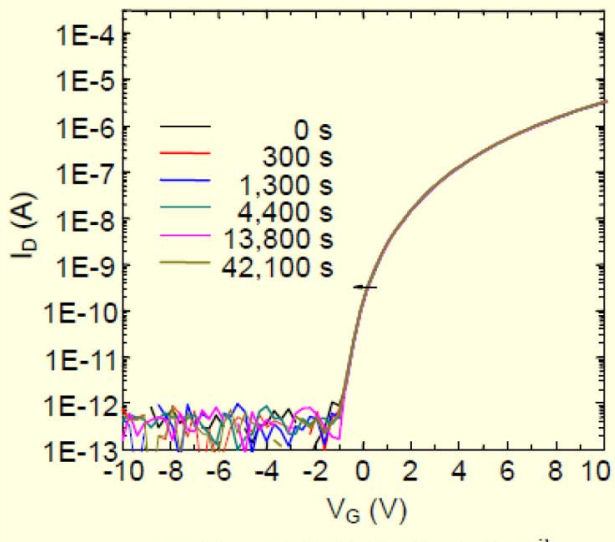

(c) $V_{G_{-} S T}=-10 \mathrm{~V}, P_{\mathrm{ill}}=0 \mathrm{~mW} / \mathrm{cm}^{2}$

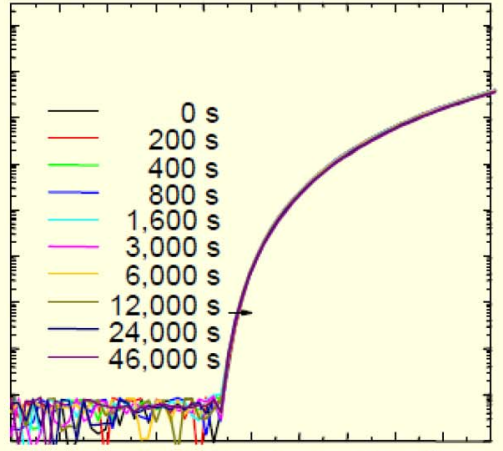

(b) $V_{G_{-} S T}=10 \mathrm{~V}, P_{\text {ill }}=1 \mathrm{~mW} / \mathrm{cm}^{2}$

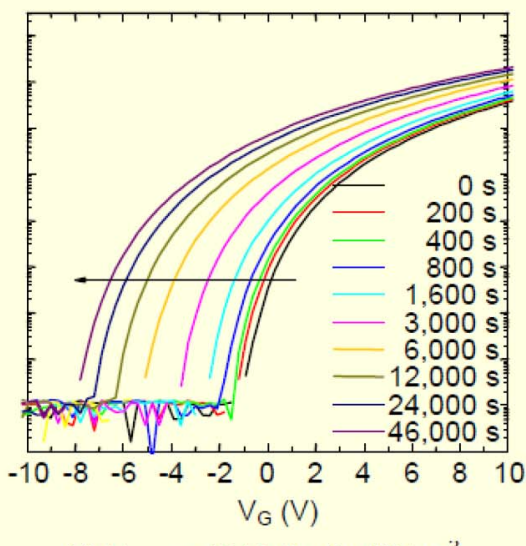

(d) $V_{G_{-}}$ST $=-10 \mathrm{~V}, P_{\mathrm{ill}}=1 \mathrm{~mW} / \mathrm{cm}^{2}$

Fig. 10. Data from the study in [57]. Plot of $I_{D}$ versus $V_{G}$ for the PE-ALD $\mathrm{Al}_{2} \mathrm{O}_{3} /$ PE-ALD ZnO TFTs exposed to either (a) and (b) positive or (c) and (d) negative $V_{G}$ stress and either (b) and (c) under simultaneous exposure to 540-nm illumination or (a) and (c) in the dark.

illumination during negative gate bias stressing at an elevated temperature. They proposed that the main mechanism for the illumination-enhanced damage is the trapping of the photogenerated holes in the gate insulator and/or at the insulator/channel interface.

6) Process Dependence of Bias Stressing: Despite the broad qualitative similarities in low-field gate bias stressing response reported for a wide variety of AOS TFT material systems, quantitative as well as qualitative differences in the response have been reported even for a given gate dielectric/AOS channel combination. TFT performance and stability can be sensitive to both channel and gate dielectric processing as well as to the details of the interface between them. Thus, some of the quantitative as well as qualitative differences in the gate bias stressing response may be attributed to processing differences (deposition method, annealing, etc.) and nonoptimized materials and interfaces. A few specific examples of the impact of 1) channel, 2) dielectric, and 3) interface processing on TFT stability are discussed. Also critical when interpreting results are ambient interaction and encapsulation (see Sections III-D and $\mathrm{E}$ ).

a) AOS channel processing: Gorrn et al. [36] showed that, depending on the composition of their PA-PLD ZTO films, positive $V_{G}$ bias stressing could produce either rigid positive $V_{T}$ shifts or negative $V_{T}$ shifts accompanied by $S$ degradation. As shown in Fig. 11, they found out that a 36\% $\mathrm{Zn}: 64 \%$ Sn composition yielded optimum stability in the ALD

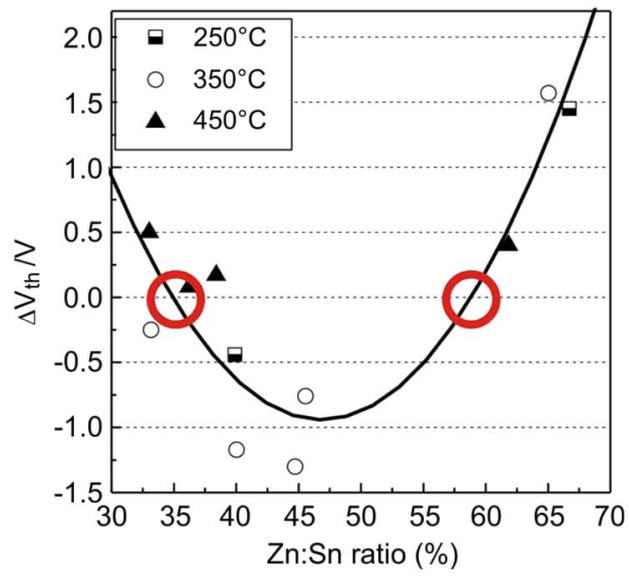

Fig. 11. Data from the study in [11]. Plot of the positive-gate-bias stressinduced $\Delta V_{T}$ versus the $\mathrm{Zn}: \mathrm{Sn}$ ratio for the ALD ATO dielectric/ZTO channel TFTs.

ATO dielectric/ZTO channel TFTs [11]. Chiang et al. [60] reported that increasing the percentage of $\mathrm{O}_{2}$ and decreasing the RF power during IGZO deposition increased the initial $V_{\mathrm{ON}}$ and improved the stability in thermal $\mathrm{SiO}_{2}$ dielectric/ RF-sputtered IGZO channel TFTs. Lim et al. [53] reported that the positive bias stress stability of ALD $\mathrm{Al}_{2} \mathrm{O}_{3}$ gate dielectric/ZnO:N channel SBG TFTs was improved with a higher $\mathrm{N}$ content. 
Postdeposition annealing of the channel can also have an impact on trapping. As an example, Nomura et al. [40] found out that $400-{ }^{\circ} \mathrm{C}$ postdeposition annealing in wet or dry $\mathrm{O}_{2}$ reduced trapping in thermal $\mathrm{SiO}_{2} / \mathrm{PLD}$ IGZO SBG TFTs, and Cho et al. [52] found out that a $4-\mathrm{h} 200-{ }^{\circ} \mathrm{C}$ anneal in air reduced $V_{T}$ shifting in thermal $\mathrm{SiO}_{2}$ gate/RF-sputtered IGZO SBG TFTs.

Jeong et al. [61] found out that the addition of Ga to solution deposited ZTO SBG TFTs improved the positive bias stress stability, which they attributed to a decrease in oxygen vacancies.

b) Gate dielectric processing: As might be expected, for a given dielectric material, deposition method and postprocessing have been reported to have an impact on bias stability. For example, Oh et al. [44] found out that bias instabilities due to RF-sputter damage of RF-sputtered $\mathrm{Al}_{2} \mathrm{O}_{3}$ gate dielectric $\mathrm{ZnO}$ TFTs were reduced when the RF-sputtered $\mathrm{Al}_{2} \mathrm{O}_{3}$ was densified by a postdeposition anneal and were nearly eliminated when ALD $\mathrm{Al}_{2} \mathrm{O}_{3}$ was used. Hoffman et al. found out that the ALD $\mathrm{HfO}_{2}$ exhibited reduced $V_{T}$ shifts compared to sputtered $\mathrm{HfO}_{2}$ for IZO SBG TFTs [45].

c) Interface: The structure of the interface has also been demonstrated to have a major impact on device stability. Lee et al. [55] and Triska et al. [43] found out that the insertion of a thin interfacial layer between the gate dielectric and the channel can either degrade or improve the interface. Lee et al. reported that the insertion of a thin $(\sim 5 \mathrm{~nm})$ interfacial layer of PECVD SiN ${ }_{x}$ between the 185-nm ALD $\mathrm{Al}_{2} \mathrm{O}_{3}$ top gate and the RF-sputtered IGZO channel resulted in a better saturation mobility, but a larger bias stress induced a $V_{T}$ shift and increased $S$. Triska et al. found out that the insertion of a thin $(\sim 3 \mathrm{~nm})$ PECVD $\mathrm{SiO}_{x}$ between the bottom 200-nm ALD $\mathrm{Al}_{2} \mathrm{O}_{3}$ gate dielectric and the RF-sputtered ZTO channel resulted in a reduced bias-stress-induced $+V_{T}$ shift, likely due to a reduced electron trapping.

7) Bias Stress Modeling and Mechanisms: The time dependence of the positive-bias-stress-induced positive $V_{T}$ shift seen in many AOS TFT systems has been fit to both logarithmic and stretched exponential models.

A logarithmic dependence on stress time is indicative of trapping at pre-existing defects with a single (small) capture cross section, without the creation of new defects [62]. The logarithmic model was used to fit the time dependence of the bias-stress-induced $V_{T}$ shift in RF-sputtered IGZO TFTs with a PECVD $\mathrm{SiN}_{x}$ gate dielectric and an $\mathrm{SiO}_{x}$ passivated IGZO surface [34] (Fig. 6), in RF-sputtered IGZO TFTs with a 5-nm interfacial PECVD $\mathrm{SiN}_{x} / \mathrm{ALD} \mathrm{Al}_{2} \mathrm{O}_{3}$ gate dielectric stack [55], in PLD IGZO TTFTs with an ALD ATO gate dielectric [39], and in RF-sputtered $\mathrm{ZnO}$ TFTs with a thermal $\mathrm{SiO}_{2}$ gate dielectric [54]. Fujii et al. [34] also found out that recovery exhibited a logarithmic time dependence.

Many other groups have observed a stretched exponential time dependence for positive-bias-stress-induced positive $V_{T}$ shift. The stretched exponential model can be expressed as

$$
\Delta V_{T}=\Delta V_{T 0}\left\{1-\exp \left[-(t / \tau)^{\beta}\right]\right\}
$$

where $V_{T 0}=$ saturation $V_{T}, t=$ time, $\tau=\tau_{0} \exp \left(E_{\tau} / k T\right)$, $\beta=$ stretched exponent, $E_{\tau}=$ channel/dielectric average energy barrier, and $E_{a}=E_{\tau} \beta$ is the thermal activation energy.

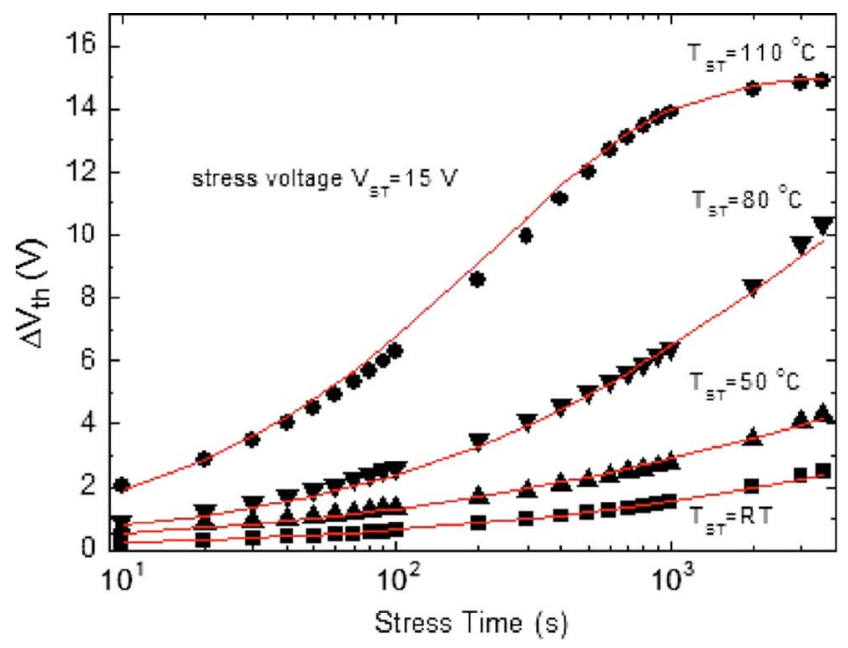

(a)

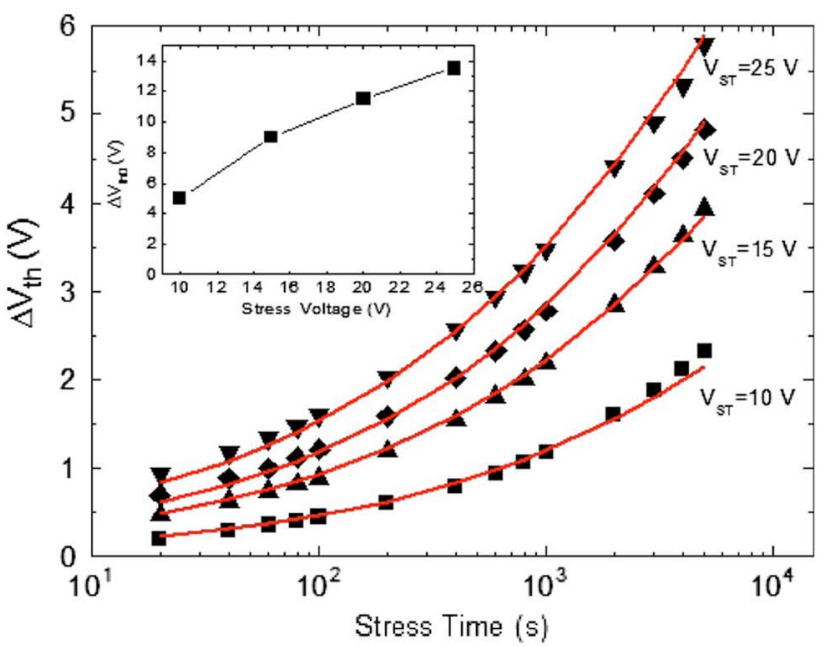

(b)

Fig. 12. Data from the study in [32]. Stretched exponential modeling of the positive-gate-bias-stress-induced $\Delta V_{\mathrm{th}}$ shift in RF-sputtered IGZO/thermally grown $\mathrm{SiO}_{2}$ top gate TFTs as a function of the (a) temperature and (b) stress voltage.

It was first used to model trapping in $a$-Si:H systems by Libsch and Kanicki [63] and it has also been used to model charge trapping in high- $\kappa$ dielectrics by Zafar et al. [64].

Lee et al. used stretched exponentials to fit the time dependence of the positive-bias-stress-induced $V_{T}$ shift in RFsputtered IGZO top gate TFTs with both thermally grown $\mathrm{SiO}_{2}$ [32] (see Fig. 12) and $\mathrm{ALD} \mathrm{Al}_{2} \mathrm{O}_{3}$ [55] gate dielectrics, and noted that the model could account for a variety of stress fields and temperatures. It is interesting to note that they saw a logarithmic fit versus time when a $5-\mathrm{nm} \mathrm{SiN}_{x}$ interfacial layer was inserted between the IGZO and $\mathrm{Al}_{2} \mathrm{O}_{3}$ [55], which they interpreted as an indication that the dielectric is the origin of the charge trapping and that charge is more easily redistributed in $\mathrm{Al}_{2} \mathrm{O}_{3}$. Nomura et al. [40] also used a stretched exponential to model positive-bias-stress-induced trapping in the PLD IGZO TFTs with thermal $\mathrm{SiO}_{2}$ as a gate dielectric. However, contrary to Lee et al., they suggested that the origin of the charge trapping was not in dielectric but either in the acceptor-like traps in the IGZO channel or at $\mathrm{IGZO} / \mathrm{SiO}_{2}$ interface. 
Triska et al. [43] found out that, although a logarithmic model fits well the positive-gate-bias-induced $V_{\mathrm{ON}}$ shift for an RF-sputtered ZTO SBG TFT with an ALD $\mathrm{Al}_{2} \mathrm{O}_{3}$ gate dielectric, a stretched exponential model was required to fit the $V_{\mathrm{ON}}$ shift if the $\mathrm{Al}_{2} \mathrm{O}_{3}$ was capped with a thin $(\sim 2-5 \mathrm{~nm})$ layer of PECVD $\mathrm{SiO}_{2}$ or if the PECVD $\mathrm{SiO}_{2}$ was used alone, indicating that the interface dominates the stress response.

Fung et al. [56] used a stretched exponential to model trapping in sputtered $\mathrm{SiO}_{2}$ encapsulated IGZO channel SBG TFTs with RF-sputtered $\mathrm{SiO}_{2}$ gate dielectrics. Good fit of the stretched exponential model to both positive and negative gate bias stressings for all stress temperatures was interpreted as carrier injection from the channel and subsequent charge trapping. The detailed fitting parameters suggested that there is a lower barrier for electron injection than for hole injection.

Lopes et al. [18] used a stretched exponential model to fit both positive $V_{T}$ shift and recovery in unencapsulated RFsputtered IGZO SBG TFTs with thermal $\mathrm{SiO}_{2}$ gate dielectrics.

Cho et al. [52] found out that positive $V_{T}$ shift and recovery in dynamically stressed thermal $\mathrm{SiO}_{2}$ gate/RF-sputtered IGZO SBG TFTs were well modeled by stretched exponentials. The modeled recovery time constant was longer than the modeled stress time constant and was decreased with increasing temperature and $V_{\mathrm{DS}}$. The authors concluded that the dominant mechanism was the trapping of the electrons in unstable traps at the interface or in the bulk with redistribution but negligible creation of additional interface traps. An incomplete recovery at room temperature suggested some deep trapping.

Shin et al. [57] used a modified stretched exponential to fit the negative-bias-stress-induced negative $V_{T}$ shift in PE-ALD $\mathrm{Al}_{2} \mathrm{O}_{3} /$ PE-ALD $\mathrm{ZnO}$ TTFTs that were simultaneously exposed to various intensities of 524-nm illumination.

Finally, Hoffman et al. [45] reported that stretched exponentials fit the positive-bias-stress-induced positive $V_{\mathrm{ON}}$ shift in ZIO channel SBG TFTs with either PECVD $\mathrm{SiO}_{2}$ or PECVD $\mathrm{SiN}_{x}$ gate dielectrics.

Both the logarithmic and stretched exponential models have been interpreted as suggesting that charge trapping without the creation of new defects dominates the bias stress response [18], [30]-[32], [34], [39], [40], [43], [52], [56], [57]. The main difference between the physical interpretations of the two models is that, while the logarithmic model was developed based on the assumption of trapping at pre-existing defects with a single cross section, with no further redistribution of the charge after initial trapping [55], the stretched exponential model represented by (1) can be arrived at by assuming either 1) a redistribution of trapped charges at long stress times and large stress fields toward energetically deeper states in the bulk dielectric, where $\beta$ relates to the energy barrier for charge distribution [63], or 2) the presence of a distribution of trap capture cross sections, where $\beta$ relates to the width of distribution [64]. Note that without the benefit of additional information about point defects such as that provided by electron spin resonance (ESR), attaching a specific physical meaning to $\beta$ is not straightforward.

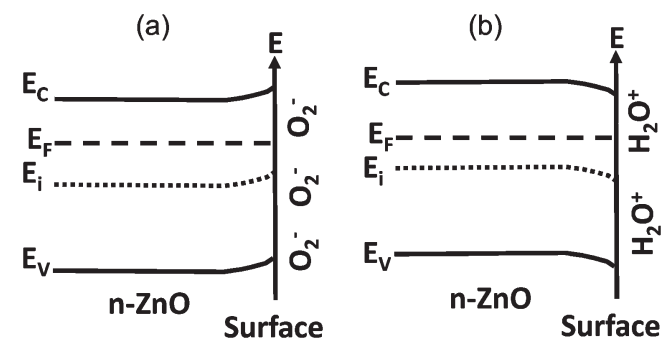

Fig. 13. Rough sketch showing the impact of (a) $\mathrm{O}_{2}^{-}$and (b) $\mathrm{H}_{2} \mathrm{O}^{+}$adsorption on band bending at an AOS surface.

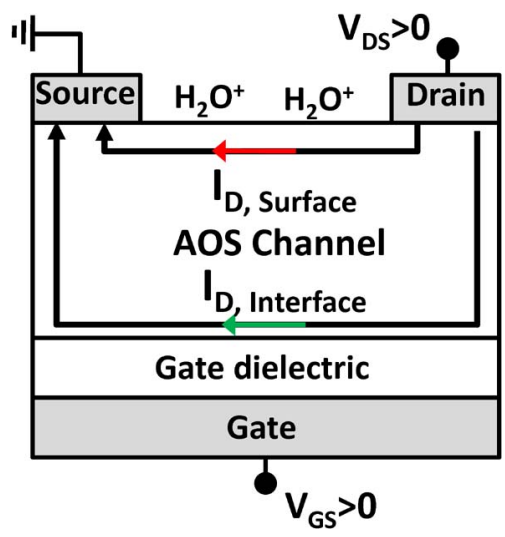

Fig. 14. Cross-sectional schematic of an unpassivated bottom gate TFT device illustrating the formation of a parasitic top gate channel due to surface adsorption [68].

\section{Surface/Ambient Interaction}

It is well known that metal oxides are surface sensitive to molecules in the ambient atmosphere [22]-[25]. For example, the adsorption of $\mathrm{O}_{2}$ onto the surface of a metal oxide introduces an acceptor-like surface state: physisorbed $\mathrm{O}_{2}$ is neutral when unoccupied and becomes chemisorbed and negatively charged $\left[\mathrm{O}_{2}\right]^{-}$when it captures (becomes occupied by) an electron from the $\mathrm{CB}$. The resultant $\left[\mathrm{O}_{2}\right]^{-}$causes in surface depletion. Similarly, $\mathrm{H}_{2} \mathrm{O}$ can act as a donor-like surface state (although the interaction of $\mathrm{H}_{2} \mathrm{O}$ with the surface is more complex [25]). Other molecules such as $\mathrm{H}_{2}, \mathrm{CO}_{2}$, ethanol, etc., can also interact with metal oxide surfaces to produce changes in conductivity. Shown in Fig. 13 are rough sketches showing surface band bending and the generation of a surface depletion region as a result of chemisorbed $\left[\mathrm{O}_{2}\right]^{-}$[Fig. 13(a)] and formation of an accumulation region as a result of chemisorbed $\left[\mathrm{H}_{2} \mathrm{O}\right]^{+}$[Fig. 13(b)] [65]-[67]. It can therefore be expected that when an SBG TFT channel is left unpassivated, as shown in Fig. 14 the surface-adsorbed $\mathrm{H}_{2} \mathrm{O}$ or other donors may result in a parallel parasitic back channel conduction path [66]-[68]. Likewise, the removal of the adsorbed $\left[\mathrm{O}_{2}\right]^{-}$can also lead to increased surface carrier density and conductivity.

Vacuum desorption experiments on unpassivated bottom gate devices, with the channel surface exposed to ambient, illustrate the impact of the surface-adsorbed species. Kang et al. [69] looked at PECVD $\mathrm{Si}_{3} \mathrm{~N}_{4} / \mathrm{RF}$-sputtered IGZO channel SBG TFTs, while Gorrn et al. [70] investigated ALD ATO/PA-PLD ZTO SBG TFTs. Both of these studies reported that upon exposure to vacuum after storage in ambient unpassivated devices 
exhibited a negative $V_{T}$ shift that is entirely reversible [69], [70]. Kang et al. further showed that postvacuum exposure to $\mathrm{O}_{2}$ resulted in a super recovery of $V_{T}$, in which $V_{T}$ overshoots the pre-exposure value to become more positive. Both groups concluded that the $V_{T}$ shift appears to be dominated by $\mathrm{O}_{2}$ desorption, but that $\mathrm{H}_{2} \mathrm{O}$ also plays a role.

In a different type of study, PECVD $\mathrm{Si}_{3} \mathrm{~N}_{4}$ dielectric/RFsputtered IGZO SBG TFTs were soaked in DI $\mathrm{H}_{2} \mathrm{O}$ and were then heated in vacuum, after which Park et al. [67] observed a positive shift, consistent with desorption of $\mathrm{H}_{2} \mathrm{O}$.

Ye et al. [71] found out that the mobility and carrier density of $\mathrm{ZnO}: \mathrm{N}$ SBG TFTs both deteriorated after several weeks in atmosphere at $50{ }^{\circ} \mathrm{C}$. Annealing at $400{ }^{\circ} \mathrm{C}$ in $\mathrm{N}_{2}$ was found to improve shelf life. They tentatively attributed the degradation to the catalyzed hydrolyzation due to the adsorbtion of water and pollutants.

Finally, Gorrn et al. [70] demonstrated that surface $\mathrm{O}_{2}$ interaction dominated the recovery response and so-called persistent photoconductivity in unencapsulated ZTO TFTs.

When taken together, these studies indicate that the surface interactions with the ambient must be considered when interpreting bias stressing and illumination studies of the unpassivated devices. Regarding illumination, it is well known that exposure to high-energy photons can result in the desorption of species from metal oxide surfaces. After the exposure is stopped, these species can take many minutes to reabsorb on the surface [22]-[25], [72]. As discussed in Section III-E, proper passivation or encapsulation of the channel surface can reduce or eliminate some ambient, bias stress, and illuminationinduced instabilities by eliminating interaction with surface species.

\section{Impact of Ambient on Bias Stressing}

The results discussed in the last section demonstrate that surface/ambient interactions can impact the stability of the unbiased unencapsulated SBG TFTs. With reference to simple equations for gas molecule adsorption (e.g., $\mathrm{O}_{2}$ (gas) $+\mathrm{e}^{-} \rightarrow$ $\mathrm{O}_{2}^{-}$(ads)), Jeong et al. [65] discuss how positive bias stressing can lead to field-induced adsorption of $\mathrm{O}_{2}$ and desorption of $\mathrm{H}_{2} \mathrm{O}$. ZnO nanowire sensor studies have also shown that gate bias can modulate gas sensitivity [72], [73]. In this section, recent results investigating the impact of ambient on bias stressing of unencapsulated SBG TFTs are discussed.

Lopes et al. [18] report that exposure of unencapsulated 40-nm RF-sputtered IGZO SBG TFTs with 100-nm thermal $\mathrm{SiO}_{2}$ dielectrics to water vapor for $24 \mathrm{~h}$ resulted in an accelerated $V_{T}$ shift upon subsequent bias stressing as compared to unexposed samples.

Liu et al. [38] found out that the stability of $50-\mathrm{nm}$ RF-magnetron-sputtered IZO coplanar bottom gate TFTs with $300-\mathrm{nm} \mathrm{Si}_{3} \mathrm{~N}_{4}$ gate dielectrics is degraded (larger $V_{T}$ shifts) when low-field positive and negative bias stressings are conducted in ambient rather than in vacuum. The authors attributed the enhanced degradation to interaction of $\mathrm{O}_{2}$ and $\mathrm{H}_{2} \mathrm{O}$ at the channel surface.

Finally, as shown in Fig. 15, Lee et al. [10] found out that the negative-bias-stress-induced negative $V_{T}$ shifts in unpassivated

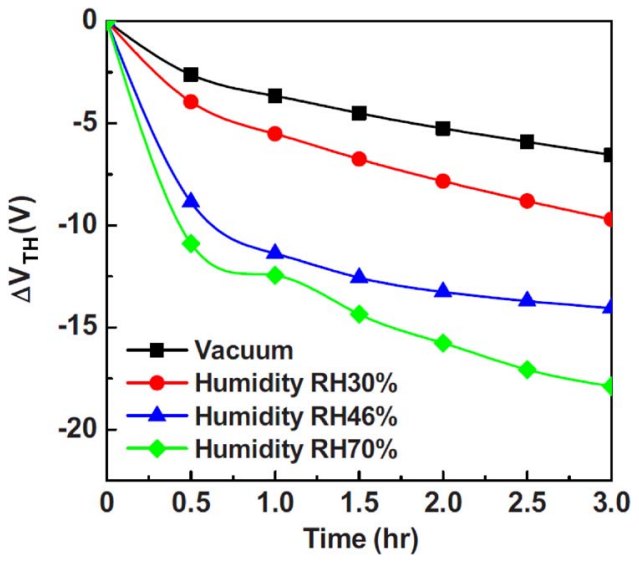

Fig. 15. Data from the study in [10]. Plot of $\Delta V_{t h}$ versus time for the unpassivated $\mathrm{SiN}_{x}$ dielectric/IGZO SBG TFTs exposed to negative gate bias stress as a function of the relative humidity.

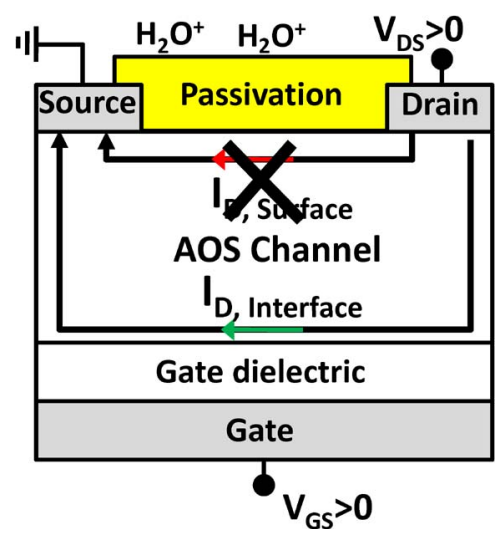

Fig. 16. Cross-sectional schematic of the passivated bottom gate TFT device illustrating the elimination of a potential parasitic top gate channel [68].

IGZO SBG TFTs with $\mathrm{SiN}_{x}$ dielectrics were progressively worse for increasing relative humidity levels from $0 \%$ to $70 \%$ humidity.

The work reviewed in this section demonstrates that ambient can have a profound impact on SBG TFT performance and stability under bias stressing and illumination. Moisture, in particular, has typically been observed to accelerate bias-stressinduced parametric shifts. It is very likely that the uncontrolled interaction of the unpassivated devices with the ambient can explain some of the differences in the illumination, bias stress, and recovery response reviewed in Section III-A and B. These results indicate that the passivation of the channel surface will likely have to be considered for the commercial applications of SBG TFTs. The effect of passivation of SBG TFTs is discussed in the next section. Note that top gate TFTs would not be expected to exhibit the same sensitivity, as they are essentially self-passivated.

\section{E. Passivation/Encapsulation and Bias Stressing}

As shown in Fig. 16, passivation or encapsulation of the AOS channel can physically prevent or kinetically inhibit [52] ambient molecules from adsorbing on AOS channel surface.

Many groups have shown that proper surface passivation can reduce or eliminate $V_{G}$ stressing instabilities in bottom gate 


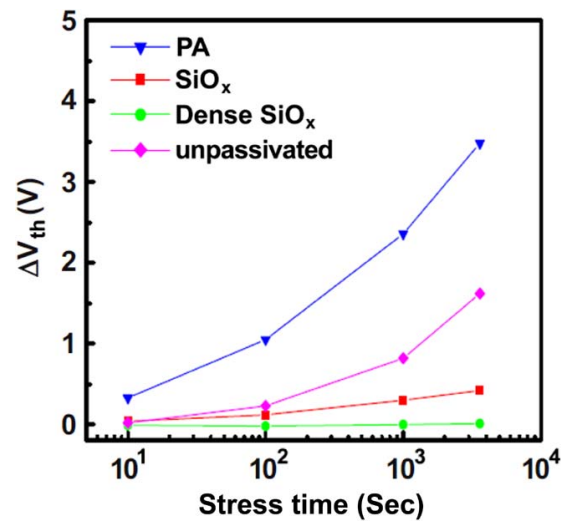

Fig. 17. Data from the study in [65]. Plot of the positive-gate-bias-stressinduced $\Delta V_{\mathrm{th}}$ versus time for the $\mathrm{SiN}_{x} / \mathrm{RF}$-sputtered IGZO SBG TFTs as a function of the channel passivation.

devices. As shown in Fig. 17, Jeong et al. [65] compared RFsputtered IGZO passivated with either organic photoacryl (PA), PECVD $\mathrm{SiO}_{x}$, or densified $\mathrm{SiO}_{x}$ with unpassivated IGZO TFTs and found out that while undensified $\mathrm{SiO}_{x}$ reduced and densified $\mathrm{SiO}_{x}$ nearly eliminated the $V_{T}$ shift during positive $V_{G}$ stressing, the PA passivated TFTs exhibited a degraded stability. Levy et al. [74] showed that $30-\mathrm{nm} \mathrm{ALD} \mathrm{Al}_{2} \mathrm{O}_{3}$ passivated ALD ZnO TFTs exhibited much less $+V_{G}$ stress-induced $V_{T}$ shift than the unpassivated devices. Many other groups have also reported dc bias stress stability improvements resulting from the passivation of a variety of AOS channel SBG TFTs including following: passivation of ZTO with a novel ALD $\mathrm{Al}_{2} \mathrm{O}_{3} / \mathrm{ZrO}_{2}$ laminate [70], polyimide passivation of AZTO [75], 25-nm ALD $\mathrm{Al}_{2} \mathrm{O}_{3}$ encapsulation of $\mathrm{Al} / \mathrm{Sn}$ doped $\mathrm{ZIO}$ [76], passivation of ZTO with a spin on $\mathrm{SiO}_{x}$ and PMMA [77], and passivation of PE-ALD $\mathrm{ZnO}$ with $\mathrm{ALD} \mathrm{Al}_{2} \mathrm{O}_{3}$ [48], [49]. Seo et al. found out that $\mathrm{TiO}_{x}$ passivation of IGZO SBG TFTs improved both negative bias stress stability and environmental stability/aging [58]. Arai et al. [14] found out that dc-sputtered $\mathrm{Al}_{2} \mathrm{O}_{3}$ passivation of IGZO SBG TFTs performed better than either RF-sputtered $\mathrm{SiO}_{x}$ or CVD $\mathrm{SiN}_{x} / \mathrm{SiO}_{x}$ passivation, whereas straight $\mathrm{CVD} \mathrm{SiN}_{x}$ passivation actually degraded performance.

Cho et al. [52] reported a reduced $V_{T}$ shift in dynamically stressed RF-sputtered IGZO SBG TFTs passivated with 100-nm RF-sputtered $\mathrm{Al}_{2} \mathrm{O}_{3}$.

Lee et al. [10] reported that a humidity-enhanced degradation during negative bias stressing was greatly reduced by 200-nm $\mathrm{SiO}_{x}$ passivation of their $\mathrm{SiN}_{x} /$ IGZO SBG TFTs.

Sato et al. [47] found out that PECVD $\mathrm{SiO}_{x} / \mathrm{Si}_{3} \mathrm{~N}_{4}$ (50/ $300 \mathrm{~nm}$ ) surface passivated IGZO channel coplanar homojunction bottom PECVD $\mathrm{SiO}_{x}$ gate TFTs that were subjected to an environmental test for $116 \mathrm{~h}$ at $85^{\circ} \mathrm{C}$ and $85 \%$ relative humidity showed only an $\sim 0.1-\mathrm{V} V_{T}$ shift, indicating that the passivation layer protects the device (Other groups [18] have reported a negative $V_{T}$ shift after exposure to humidity.).

Finally, Oh et al. [44] saw that for $\mathrm{ALD} \mathrm{Al}_{2} \mathrm{O}_{3} / \mathrm{RF}$-sputtered $\mathrm{ZnO}$ TFTs, use of top gate structure resulted in less positivebias-stress-induced degradation than a bottom gate structure, even when the top gate structure was stressed at a $70 \%$ higher field.
Passivation can have unwanted side effects as well. For example, passivation has been reported to impact base device parameters for unstressed devices. Several groups have reported that passivated devices exhibit a negatively shifted $V_{T}$ as compared to unpassivated devices, with no change in $S$ or $\mu$, including Gorrn et al. [70] (ALD $\mathrm{Al}_{2} \mathrm{O}_{3} / \mathrm{ZrO}_{2}$ laminate passivated ZTO), Levy et al. [78] (ALD $\mathrm{Al}_{2} \mathrm{O}_{3}$ passivated $\mathrm{ZnO})$, and Hong and Wager [68] $\left(\mathrm{SiO}_{x}, \mathrm{CaF}, \mathrm{GeO}_{x}, \mathrm{SrF}\right.$, and $\mathrm{SbO}_{x}$ passivation of ZTO). This negative $V_{T}$ shift is thought to be due to $\mathrm{O}_{2}$ removal from the surface, leading to generation of higher carrier densities. Hong et al. [68] reported that $\mathrm{NiO}_{x}$ passivation of ZTO reduced peak mobility. Zhao et al. [48] and Mourey et al. [49] reported that $\mathrm{ALD} \mathrm{Al}_{2} \mathrm{O}_{3}$ passivation of PEALD $\mathrm{Al}_{2} \mathrm{O}_{3} / \mathrm{PE}-\mathrm{ALD} \mathrm{ZnO}$ resulted in an $\sim 2-\mathrm{V}$ shift in $V_{T}$ and an increased $S$ but with a reduced hysteresis. In another work, the spin coat polyimide passivation of AZTO improved $S$ [76].

In summary, it is clear from the work discussed in this section that passivation can play a major role in TFT performance and stability. In order to be effective, the passivating layer must be compatible with the underlying channel layer, must be thick enough to eliminate the influence of surface-adsorbed species, must be a good enough diffusion barrier to eliminate the diffusion of surface species to the passivating layer/channel interface, and should have a low hydrogen content [13], [68]. Proper passivation can reduce or eliminate surface- and bias-stressinduced instabilities in bottom gate devices without impacting the base device parameters. A careful passivation is thought to be critical in producing stable SBT TFTs for commercial applications [12]-[14]. Passivation is not as much of a concern for top gate devices which are self-passivated by the overlying gate dielectric.

\section{F. Mechanical Stress}

For flexible circuit applications, it is important to know the impact of mechanical strain and flexing on TFT stability. Nomura et al. [7] looked at the impact of bending-induced tensile stress on unencapsulated 140-nm PLD Y ${ }_{2} \mathrm{O}_{3}$ dielectric/ 30-nm PLD IGZO SBG TTFTs and found out that the application of $0.3 \%$ tensile strain resulted in a slight decrease in saturation current, but that the devices were stable when subjected to repetitive bending.

\section{G. Defects}

A fundamental understanding of the structure and nature of point defects that are responsible for electrically induced instabilities is often necessary in fully optimizing the material and device performance. Electron paramagnetic resonance (EPR), also known as ESR, is the only technique that can provide detailed structural information about electrically active point detects [79]. EPR studies have identified dominant electrically active defects in both $\mathrm{Si} / \mathrm{SiO}_{2}$ and $a-\mathrm{Si}: \mathrm{H} / \mathrm{Si}_{3} \mathrm{~N}_{4}$ systems.

For $\mathrm{Si} / \mathrm{SiO}_{2}$ system, EPR studies have shown that two types of $\mathrm{Si}$ dangling bond centers dominate the performance and reliability of MOS devices: $P_{b}$ centers $\left(\mathrm{Si}_{3} \equiv \mathrm{Si} \bullet\right)$ at the $\mathrm{Si} / \mathrm{SiO}_{2}$ interface and $E^{\prime}$ centers $\left(\mathrm{O}_{3} \equiv \mathrm{Si \bullet}\right)$ in the $\mathrm{SiO}_{2}$ [79]-[81]. For the $a-\mathrm{Si}: \mathrm{H} / \mathrm{Si}_{3} \mathrm{~N}_{4}$ system, EPR studies have also shown that the silicon dangling bond centers are dominant: D-centers 
$\left(\mathrm{Si}_{3} \equiv \mathrm{Si} \bullet\right)$ in the $a$-Si:H [82] are created by illumination [2] and bias stressing [1], and $\mathrm{K}$ centers $\left(\mathrm{N}_{3} \equiv \mathrm{Si} \bullet\right)$ are populated by charge injection into the $\mathrm{Si}_{3} \mathrm{~N}_{4}$ [83]. The understanding of these defects has allowed both of these technologies to flourish.

EPR investigations have also begun to shed light on electrically active and stress-induced defects in thin-film high- $\kappa$ dielectrics [84]. In bulk $\mathrm{ZnO}$ powder, EPR studies have shown that oxygen vacancies are likely responsible for the green luminesence [85]. Very recently, Jeong et al. [61] observed an EPR resonance with a Landé $g$-factor equal to 1.9559 in solution-deposited Ga doped and undoped ZTO films, which they tentatively assigned to oxygen vacancies $\left(V_{O}\right)$. They also reported that the $40 \%$ lower spin density that they saw in Ga doped ZTO was accompanied by a reduction in the bias-stress-induced $V_{T}$ shift, suggesting that this defect may play a role in the bias stress stability of these devices. With the exception of the study in [61], there have been no dedicated EPR investigations performed on thin-film AOS materials and no consideration of any of the many combinations of high- $\kappa$ dielectric/AOS channel interfaces that are being used to make TFTs.

Although groups have begun to map the subgap density of states in IGZO [21], [86], [87] and ZTO [26], which is useful in understanding device performance and mobility, the identification of the defect structures that are responsible for instabilities in AOS TFTs remains a wide open field. To date, there is no direct experimental evidence linking specific defect structures to bias-stress-induced instabilities. Much work needs to be done to understand the nature of the defects in the AOS materials, in high- $\kappa$ dielectrics, and especially at AOS/dielectric interface in the AOS TFTs.

\section{SUMmary/CONCLUSION}

Novel AOS TFT channel materials such as ZTO, IGZO, ZITO, etc., exhibit several advantages over $a$-Si:H TFTs, such as mobility in the range of $\sim 5->50 \mathrm{~cm}^{2} / \mathrm{V} \cdot \mathrm{s}$, low temperature processing, and transparency in the visible portion of the spectrum [6]. An obvious application of these materials is transparent electronics. Although it will be difficult to displace $a$-Si:H, especially for large-area displays, another potential application for AOS TFTs is as backplanes for high-performance AMLCDs. Probably the most likely target application for these new materials is using them as an AM-TFT backplane for the emerging OLED display technology. For the first two applications, TFTs need to remain stable while operating under continuous exposure to illumination. Because OLED displays are emissive and current driven, TFT stability is critical as any shift in $V_{T}$ would result in a change in pixel brightness [6], [11], [15]-[18]. $V_{T}$ stability under a gate bias stress is recognized as one of the most significant issues in commercializing AOS TFT technology for AMOLED displays [13], [14].

Despite its importance, investigation of AOS TFT stability is still an emerging area. The first TTFTs were reported in 2003. The first paper on ZnO TFT stability under bias stressing was published in 2006 [30]. Since then, the number of stabilityrelated AOS TFT papers has roughly doubled each year. A number of potential reliability problems have been identified and have begun to be investigated in a number of combinations of AOS channels and gate dielectrics. Direct comparisons of the studies to date are difficult due to the details of the materials, device structure, and stress conditions, and there have been a few extensive systematic studies. Nevertheless, some general trends can be identified with respect to stability under the following: 1) illumination; 2) bias stress; and 3) channel surface/ambient interaction.

Illumination: although $a$-Si:H devices exhibit well-known instabilities upon exposure to visible illumination that results in permanent changes, the AOS materials, in general, exhibit little sensitivity to ambient lighting, reversible changes as the photon energy approaches the bandgap, and no permanent changes even upon exposure to high-energy illumination [27]-[29]. Sensitivity to illumination can be minimized by encapsulation and by using UV absorbing coatings which would not impact applications requiring transparency in the visible part of the spectrum [27].

Bias stressing: bias stressing of the $a-\mathrm{Si}: \mathrm{H} / \mathrm{Si}_{3} \mathrm{~N}_{4}$ TFTs results in defect creation in the channel and charge trapping gate dielectric or at channel/dielectric interface that is irreversible without annealing. AOS TFTs have also been found to be sensitive to bias stressing. In contrast to $a$-Si:H, the majority of the AOS TFT studies to date suggest that instability problems due to low-field positive gate bias stress can be explained by trapping and detrapping at pre-existing defects at or near dielectric/channel interface, with little creation of new defects, and rapid recovery without annealing [18], [30]-[49], [52], [53]. This general result is consistent with the suggestion that the nature of bonding in AOS materials (e.g., carrier conduction through metal ns orbitals instead of covalent $s p^{3}$ orbitals [7]) affords them a greater resistance to defect and dangling bond formation than $a-\mathrm{Si}: \mathrm{H}$ [8], [9]. Defect creation and recovery that requires annealing have been reported in some studies of high-field ( $>1 \mathrm{MV} / \mathrm{cm}$ ) stressing [30], [54], [55], and they are topics that require more investigation.

Ambient interaction: the majority of the AOS TFTs investigated to date are SBG devices without passivation, in which the AOS channel surface is left exposed to ambient. The surface sensitivity of metal oxides is well known. For example, adsorption and desorption of molecules from ambients such as $\mathrm{O}_{2}, \mathrm{H}_{2} \mathrm{O}$, etc., can result in the accumulation or depletion of the surface region and can affect the conductivity and performance of the device [65]-[70]. Thus, the impact of surface interactions on the unpassivated devices cannot be ignored when interpreting bias stress results. Indeed, channel surface/ambient interaction has recently been demonstrated to have a significant impact on both bias and illumination stressing of the SBG TFTs [10], [18], [41]. As surface effects were not fully taken into consideration in many of the early studies, in addition to the obvious importance of processing, they might explain a large part of the discrepancies reported between different studies for otherwise similar material systems. Fortunately, the surfaceinduced instabilities in the SBG TFTs can be reduced or eliminated either by a proper passivation of top and back-channel surface of the AOS channel or by a top-gate device structure in which the gate oxide self-passivates the AOS channel [10], [44]-[49], [52], [65], [68], [70]-[77]. 
Given this general summary of what is known so far, what are the challenges in improving the stability and reliability of the AOS TFTs for commercial applications? I believe that the main challenges include the following: 1) finding the right dielectric for a given channel material; 2) proper passivation; 3) application-directed characterization; and 4) defect identification.

Materials and the AOS/dielectric interface: it is well known that the interface between a channel material and the dielectric can have a large impact on field-effect transistor operation and stability. Just as $\mathrm{Si}_{3} \mathrm{~N}_{4}$ has allowed $a: \mathrm{SiH}$ to enjoy a huge commercial success, the identification of the best dielectric for each AOS channel material such as IGZO and ZTO is needed to allow these materials to reach their full commercial potential. Although much of the work to date has used thermally grown $\mathrm{SiO}_{2}$ as a bottom gate dielectric, thermally grown $\mathrm{SiO}_{2}$ is not compatible with transparent applications. More work is needed in which high- $\kappa$ dielectric materials deposited by various methods are systematically compared on the same channel in order to identify the most promising dielectric/AOS channel combinations [43], [45], [46], [51]. Once promising combinations have been identified, process optimization can target further improvements in stability.

Passivation: it has been recently demonstrated that proper passivation of the AOS channel surface can eliminate the influence of ambient and, in some cases, can improve bias stability. However, other work has shown that improper passivation does not prevent surface interaction or can have unwanted side effects such as $V_{T}$ shift and reduced mobility [48], [49], [68], [70], [78]. A suitable passivation layer should eliminate the effect of ambient interaction without deleteriously affecting device operation. Without proper passivation, stability results on a given device cannot be viewed as conclusive, and it is now widely agreed that passivation is critical for commercial AOS TFT applications [12]-[14]. Much work still needs to be done to identify the passivation layers that are suitable for a given AOS material. As the case for gate dielectrics, it is unlikely that a single material can serve as a suitable passivation layer for all channel materials.

Application-directed characterization: so far, the majority of the work investigating the stability of the AOS TFTs has been on single devices subjected to a single type of stress. Although this is necessary and very useful, with the strong drive toward commercialization, the next step is to assess stability and reliability under projected use conditions. Several questions need to be answered about appropriate stress conditions, multiple stressing, recovery, and mitigation. For example, for a given AOS/dielectric TFT combination, is single device bias stressing too harsh or too conservative? If one wishes to save time and perform accelerated stress at elevated fields, will the damage mechanisms remain the same? Does exposure of a device simultaneously to multiple types of stress lead to unanticipated interactions? Switching TFTs in AMLCDs will be subjected to continuous illumination from the backlight. It has very recently been shown that simulated backlight illumination exacerbates the negative-bias-stress-induced $V_{T}$ shift [10], [57]. Much more work needs to be done to test passivated devices under simultaneous bias stressing and illumination.
However, another issue is the widely reported rapid recovery of $V_{T}$ shift in unbiased devices at room temperature. This recovery contributes to a complex time dependence that will have to be well understood and modeled for circuit applications. As an example, it has been shown that due to the effects of recovery, $V_{T}$ shift is a function of stress frequency-higher frequency dynamic stressing results in less damage than static stressing [52], [59]. Finally, is parametric drift a problem for the intended application, or can some level of device deterioration be tolerated or mitigated? Recent work has shown that active mitigation such as $V_{T}$ compensation circuitry can be used for some AOS devices [13].

Defects: knowledge of the structure of the defects that are responsible for the instabilities can greatly aid in the reduction of these defects and in the optimization of performance and stability. For example, a strong understanding of defects at $\mathrm{Si} / \mathrm{SiO}_{2}$ interface helped in enabling the MOS technology to become the dominant microelectronics technology. Likewise, an understanding of the $a-\mathrm{Si}: \mathrm{H} / \mathrm{Si}_{3} \mathrm{~N}_{4}$ interface enabled this technology to dominate TFT applications. It is likely that an equivalent basic understanding of the defects that are responsible for instabilities in AOS TFTs for specific AOS/gate dielectric systems will be critical before the commercial application in OLED displays or other areas such as flexible electronics can be realized. This area, in particular, is ripe for more work.

In conclusion, initial reports suggest that AOS TFTs exhibit promising stability compared to $a-\mathrm{Si}: \mathrm{H}$ with respect to illumination and bias stressing. If these instabilities can be fully understood and minimized, AOS technology has a bright future.

\section{ACKNOWLEDGMENT}

The author would like to thank Prof. J. Wager from Oregon State University for the technical discussions and B. Yeh from Hewlett Packard for the careful review of the manuscript. This paper grew out of an invited talk presented at 2009 IEEE International Integrated Reliability Workshop.

\section{REFERENCES}

[1] M. J. Powell, C. van Berkel, I. D. French, and D. H. Nichols, "Bias dependence of instability mechanisms in amorphous silicon thin film transistors," Appl. Phys. Lett., vol. 51, no. 16, pp. 1242-1244, Oct. 1987.

[2] D. L. Staebler and C. R. Wronski, "Reversible conductivity changes in discharge produced amorphous Si," Appl. Phys. Lett., vol. 31, no. 4, pp. 292-294, Aug. 1977.

[3] R. L. Hoffman, B. J. Norris, and J. F. Wager, “ $\mathrm{ZnO}$ based transparent thin film transistors," Appl. Phys. Lett., vol. 82, no. 5, pp. 733-735, Feb. 2003.

[4] P. F. Carcia, R. S. McLean, M. H. Reilly, and G. Nunes, Jr., "Transparent $\mathrm{ZnO}$ thin-film transistor fabricated by RF magnetron sputtering," Appl. Phys. Lett., vol. 82, no. 7, pp. 1117-1119, Feb. 2003.

[5] K. Nomura, K. Ohta, K. Ueda, T. Kamiya, M. Hirano, and H. Hosono, "Thin film transistor fabricated in single crystal transparent oxide semiconductor," Science, vol. 300, no. 5623, pp. 1269-1272, May 2003.

[6] J. F. Wager, D. A. Keszler, and R. A. Presley, Transparent Electronics. New York: Springer-Verlag, 2008.

[7] K. Nomura, H. Ohta, A. Takagi, T. Kamiya, M. Hirano, and H. Hosono, "Room-temperature fabrication of transparent flexible thin-film transistors using amorphous oxide semiconductors," Nature, vol. 432, no. 7016, pp. 488-492, Nov. 2004.

[8] J. Robertson, "Disorder, band offsets, and dopability of transparent conducting oxides," Thin Solid Films, vol. 516, no. 7, pp. 1419-1425, Feb. 2008.

[9] J. Robertson, "Physics of amorphous conducting oxides," J. Non-Cryst. Solids, vol. 354, no. 19-25, pp. 2791-2795, May 2008. 
[10] K. H. Lee, J. S. Jung, K. S. Son, J. S. Park, T. S. Kim, R. Choi, J. K. Jeong, J. Y. Kwon, B. Koo, and S. Lee, "The effect of moisture on the photon-enhanced negative bias thermal instability in Ga-In-Zn-O thin film transistors," Appl. Phys. Lett., vol. 95, no. 23, p. 232 106, Dec. 2009.

[11] T. Riedl, P. Gorrn, and W. Kowalsky, "Transparent electronics for seethrough AMOLED displays," J. Display Technol., vol. 5, no. 12, pp. 501508, Dec. 2009.

[12] H. H. Lu, H. C. Ting, T. H. Shih, C. Y. Chen, C. S. Chuang, and Y. Lin, "76.3: 32-inch LCD panel using amorphous indium-gallium-zinc-oxide TFTs," in Proc. SID Dig., 2010, pp. 1136-1138.

[13] Y. G. Mo, M. Kim, C. K. Kang, J. H. Jeong, Y. S. Park, C. G. Choi, H. D. Kim, and S. S. Kim, "69.3: Amorphous oxide TFT backplane for large size AMOLED TVs," in Proc. SID Dig., 2010, pp. 1037-1040.

[14] T. Arai, N. Morosawa, K. Tokunaga, Y. Terai, E. Fukumoto, T. Fujimori, T. Nakayama, T. Yamaguchi, and T. Sasaoka, "69.2: Highly reliable oxidesemiconductor TFT for AM-OLED display," in Proc. SID Dig., 2010, pp. 1037-1040.

[15] J. K. Jeong, S. Yang, D. H. Cho, S. H. K. Park, C. S. Hwang, and K. I. Cho, "Impact of device configuration on the temperature instability of Al-ZnSn-O thin film transistors," Appl. Phys. Lett., vol. 95, no. 12, p. 123 505, Sep. 2009

[16] P. Gorrn, M. Sander, J. Meyer, M. Kroger, E. Becker, H. J. Johannes, W. Kowalsky, and T. Riedl, "Towards see-through displays: Fully transparent thin-film transistors driving transparent organic light-emitting diodes," Adv. Mater., vol. 18, no. 6, pp. 738-741, Mar. 2006.

[17] P. Gorrn, F. Ghaffari, T. Riedl, and W. Kowalsky, "Zinc tin oxide based driver for highly transparent active matrix OLED displays," Solid State Electron., vol. 53, no. 3, pp. 329-331, Mar. 2009.

[18] M. E. Lopes, H. L. Gomes, M. C. R. Medeiros, P. Barquinha, L. Pereira, E. Fortunato, R. Martins, and I. Ferreira, "Gate-bias stress in amorphous oxide semiconductors thin-film transistors," Appl. Phys. Lett., vol. 95, no. 6, p. 063502 , Aug. 2009.

[19] M. Powell, "The physics of amorphous-Si thin-film transistors," IEEE Trans. Electron Devices, vol. 36, no. 12, pp. 2753-2763, Dec. 1989.

[20] Ü. Özgür, Y. I. Alivov, C. Liu, A. Teke, M. A. Reshchikov, S. Dogan, V. Avrutin, S.-J. Cho, and H. Morkoç, "A comprehensive review of ZnO materials and devices," J. Appl. Phys., vol. 98, no. 4, p. 041301 , Aug. 2005.

[21] K. Nomura, T. Kamiya, H. Yanagi, E. Ikenaga, K. Yang, K. Kobayashi, M. Hirano, and H. Hosono, "Subgap states in transparent amorphous oxide semiconductor, In-Ga-Zn-O, observed by bulk sensitive X-ray photoelectron spectroscopy," Appl. Phys. Lett., vol. 92, no. 20, p. 202 117, May 2008.

[22] A. Kolmakov and M. Moskovits, "Chemical sensing and catalysis by onedimensional metal-oxide nanostructures," Annu. Rev. Mater. Res., vol. 34, pp. 151-180, 2004.

[23] Z. Fan, D. Wang, P. C. Chang, W. Y. Tseng, and J. G. Lu, "ZnO nanowire field-effect transistor and oxygen sensing property," Appl. Phys. Lett., vol. 85, no. 24, pp. 5923-5925, Dec. 2004.

[24] J. F. Conley, Jr., L. Stecker, and Y. Ono, "Directed integration of $\mathrm{ZnO}$ nanobridge devices on a Si substrate using a $\mathrm{ZnO}$ seed layer," Appl. Phys. Lett., vol. 87, no. 22, p. 223114 , Nov. 2005.

[25] Y. Li, F. Della Valle, M. Simonet, I. Yamada, and J. J. Delaunay, "Competitive surface effects of oxygen and water on UV photoresponse of $\mathrm{ZnO}$ nanowires," Appl. Phys. Lett., vol. 94, no. 2, p. 023 110, Jan. 2009.

[26] P. T. Erslev, E. S. Sundholm, R. E. Presley, D. Hong, J. F. Wager, and J. D. Cohen, "Mapping out the distribution of electronic states in the mobility gap of amorphous zinc tin oxide," Appl. Phys. Lett., vol. 95, no. 19, p. 192115 , Nov. 2009.

[27] P. Gorrn, M. Lehnhardt, T. Riedl, and W. Kowalsky, "The influence of visible light on transparent zinc tin oxide thin film transistors," Appl. Phys. Lett., vol. 91, no. 19, p. 193 504, Nov. 2007.

[28] D. C. Paine, B. Yaglioglu, Z. Beiley, and S. Lee, "Amorphous IZObased transparent thin film transistors," Thin Solid Films, vol. 516, no. 17, pp. 5894-5898, Jul. 2008.

[29] P. Barquinha, A. Pimentel, A. Marques, L. Pereira, R. Martins, and E. Fortunato, "Effect of UV and visible light radiation on the electrical performances of transparent TFTs based on amorphous indium zinc oxide," J. Non-Cryst. Solids, vol. 352, no. 9-20, pp. 1756-1760, Jun. 2006.

[30] R. B. M. Cross and M. M. De Souza, "Investigating the stability of ZnO thin film transistors," Appl. Phys. Lett., vol. 89, no. 26, p. 263513 , Dec. 2006.

[31] Y. Vygraneko, K. Wang, and A. Nathan, "Stable indium oxide thin-film transistors with fast threshold voltage recovery," Appl. Phys. Lett., vol. 91, no. 26, p. 263508 , Dec. 2007.

[32] J. M. Lee, I. T. Cho, J. H. Lee, and H. I. Kwon, "Bias-stressinduced stretched-exponential time dependence of threshold voltage shift in InGaZnO thin film transistors," Appl. Phys. Lett., vol. 93, no. 9, p. 093 504, Sep. 2008.

[33] W. Lim, S. Kim, Y. L. Wang, J. W. Lee, D. P. Norton, S. J. Pearton, F. Ren, and I. I. Kravchenko, "Stable room temperature deposited amorphous $\mathrm{InGaZnO}_{4}$ thin film transistors," J. Vac. Sci. Technol. B, Microelectron. Nanometer Struct., vol. 26, no. 3, pp. 959-962, May 2008.

[34] M. Fujii, H. Yano, T. Hatayama, Y. Uraoka, T. Fuyuki, J. S. Jung, and J. Y. Kwon, "Thermal analysis of degradation in $\mathrm{Ga}_{2} \mathrm{O}_{3}-\mathrm{In}_{2} \mathrm{O}_{3}-\mathrm{ZnO}$ thin-film transistors," Jpn. J. Appl. Phys., vol. 47, no. 8, pp. 6236-6240, Aug. 2008.

[35] S. J. Seo, C. G. Choi, Y. H. Hwang, and B. S. Bae, "High performance solution-processed amorphous zinc tin oxide thin film transistor," J. Phys. D, Appl. Phys., vol. 42, no. 3, p. 035 106, Feb. 2009.

[36] P. Gorrn, P. Holzer, T. Riedl, W. Kowalsky, J. Wang, T. Weimann, P. Hinze, and S. Kipp, "Stability of transparent zinc tin oxide transistors under bias stress," Appl. Phys. Lett., vol. 90, no. 6, p. 063 502, Feb. 2007.

[37] Y. Vygranenko, K. Wang, R. Chaji, M. Vieira, J. Robertson, and A. Nathan, "Stability of indium oxide thin film transistors by reactive ion beam assisted deposition," Thin Solid Films, vol. 517, no. 23, pp. 63416344, Oct. 2009.

[38] P. T. Liu, Y. T. Chou, and L. F. Teng, "Environment-dependent metastability of passivation-free indium zinc oxide thin film transistor after gate bias stress," Appl. Phys. Lett., vol. 95, no. 23, p. 233504 , Dec. 2009.

[39] A. Suresh and J. F. Muth, "Bias stress stability of indium gallium zinc oxide channel based transparent thin film transistors," Appl. Phys. Lett., vol. 92 , no. 3, p. 033 502, Jan. 2008.

[40] K. Nomura, T. Kamiya, M. Hirano, and H. Hosono, "Origins of threshold voltage shifts in room-temperature deposited and annealed a-In-Ga-ZnO thin-film transistors," Appl. Phys. Lett., vol. 95, no. 1, p. 013502 , Jul. 2009.

[41] K. Hosino, D. Hong, H. Q. Chiang, and J. F. Wager, "Constant-voltage bias-stress testing of a-IGZO thin-film transistors," IEEE Trans. Electron Devices, vol. 56, no. 7, pp. 1365-1370, Jul. 2009.

[42] T. Riedl, P. Gorrn, P. Holzer, and W. Kowalsky, "Ultra-high long-term stability of oxide-TTFTs under current stress," Phys. Stat. Sol. (RRL), vol. 1, no. 5, pp. 175-177, Oct. 2007.

[43] J. Triska, J. F. Conley, Jr., R. Presley, and J. F. Wager, "Positive bias stress stability of zinc-tin-oxide thin film transistors with $\mathrm{Al}_{2} \mathrm{O}_{3}$ gate dielectrics," J. Vac. Sci. Technol. B, Microelectron. Nanometer Struct., vol. 28, no. 4, pp. C5I1-C5I6, Jul. 2010.

[44] M. S. Oh, K. Lee, J. H. Song, B. H. Lee, M. M. Sung, D. K. Hwang, and S. Im, "Improving the gate stability of $\mathrm{ZnO}$ thin film transistors with aluminum oxide dielectric layers," J. Electrochem. Soc., vol. 155, no. 12, pp. H1 009-H1 014, 2008.

[45] R. Hoffman, T. Emery, B. Yeh, T. Koch, and W. Jackson, "21.4: Zinc indium oxide thin-film transistors for active-matrix display backplane," in Proc. SID Dig., 2010, pp. 288-291

[46] J. Lee, J. S. Park, Y. S. Pyo, D. B. Lee, E. H. Kim, D. Stryahilev, T. W. Kim, D. U. Jin, and Y. G. Mo, "The influence of the gate dielectrics on threshold voltage instability in amorphous indium-gallium-zinc oxide thin film transistors," Appl. Phys. Lett., vol. 95, no. 12, p. 123 502, Sep. 2009.

[47] A. Sato, M. Shimada, K. Abe, R. Hayashi, H. Kumomi, K. Nomura, T. Kamiya, M. Hirano, and H. Hosono, "Amorphous In-Ga-Zn-O thinfilm transistor with coplanar homojunction structure," Thin Solid Films, vol. 518 , no. 4, pp. 1309-1313, Dec. 2009.

[48] D. Zhao, D. A. Mourney, and T. N. Jackson, "Fast flexible plastic substrate $\mathrm{ZnO}$ circuits," IEEE Electron Device Lett., vol. 31, no. 4, pp. 323-325, Apr. 2010.

[49] D. A. Mourey, D. A. Zhao, J. Sun, and T. N. Jackson, "Fast PEALD ZnO thin film transistor circuits," IEEE Trans. Electron Devices, vol. 57, no. 2, pp. 530-534, Feb. 2010.

[50] A. J. Flewitt, J. D. Dutson, P. Beecher, D. Paul, S. J. Wakeham, M. E. Vickers, C. Ducati, S. P. Speakman, W. I. Milne, and M. J. Thwaites, "Stability of thin film transistors incorporating a zinc oxide or indium zinc oxide channel deposited by a high rate sputtering process," Semicond. Sci. Technol., vol. 24, no. 8, p. 085002 , Aug. 2009.

[51] P. Barquinha, L. Pereira, G. Gonçalves, R. Martins, D. Kuščer, M. Kosec, and E. Fortunato, "Performance and stability of low temperature transparent thin-film transistors using amorphous multicomponent dielectrics," J. Electrochem. Soc., vol. 156, no. 11, pp. H824H831, 2009.

[52] I. T. Cho, J. M. Lee, J. H. Lee, and H. I. Kwon, "Charge trapping and detrapping characteristics in amorphous InGaZnO TFTs under static and dynamic stresses," Semicond. Sci. Technol., vol. 24, no. 1, p. 015013, Jan. 2009. 
[53] S. J. Lim, J. M. Kim, D. Kim, S. Kwon, J. S. Park, and H. Kim, “Atomic layer deposition $\mathrm{ZnO}: \mathrm{N}$ thin film transistor: The effects of $\mathrm{N}$ concentration on the device properties," J. Electrochem. Soc., vol. 157, no. 2, pp. H214H218, 2010.

[54] R. B. M. Cross and M. M. De Souza, "The effect of gate-bias stress and temperature on the performance of $\mathrm{ZnO}$ thin film transistors," IEEE Trans. Device Mater. Rel., vol. 8, no. 2, pp. 277-282, Jun. 2008.

[55] J. M. Lee, I. T. Cho, J. H. Lee, W. S. Cheong, C. S. Hwang, and H. I. Kwon, "Comparative study of electrical instabilities in top-gate InGaZnO transistors with $\mathrm{Al}_{2} \mathrm{O}_{3}$ and $\mathrm{Al}_{2} \mathrm{O}_{3} / \mathrm{SiN}_{x}$ gate dielectrics," Appl. Phys. Lett., vol. 94, no. 22, p. 222 112, Jun. 2009.

[56] T. Z. Fung, K. Abe, H. Kumomi, and J. Kanicki, "Electrical instability of RF sputter amorphous In-Ga-Zn-O thin-film transistors," J. Display Technol., vol. 5, no. 12, pp. 452-461, Dec. 2009.

[57] J. J. Shin, J. S. Lee, C. S. Hwang, S. H. K. Park, W. S. Cheong, M. Ryu, C. W. Byun, J. I. Lee, and H. Y. Chu, "Light effects on the bias stability of transparent $\mathrm{ZnO}$ thin film transistors," ETRI J., vol. 31, no. 1, pp. 62-64, Feb. 2009.

[58] H.-S. Seo, J.-U. Bae, D.-H. Kim, Y. Park, C.-D. Kim, I. B. Kang, I.-J. Chung, J.-H. Choi, and J.-M. Myoung, "Reliable bottom gate amorphous indium-gallium-zinc oxide thin-film transistors with $\mathrm{TiO}_{x}$ passivation layer," Electrochem. Solid-State Lett., vol. 12, no. 9, pp. H348-H351, 2009.

[59] J. S. Suehle and P. Chaparala, "Low electric field breakdown of thin $\mathrm{SiO}_{2}$ films under static and dynamic stress," IEEE Trans. Electron Devices, vol. 44, no. 5, pp. 801-808, May 1997.

[60] H. Q. Chiang, B. R. McFarlane, D. Hong, R. E. Presley, and J. F. Wager, "Processing effects on the stability of amorphous indium gallium zinc oxide thin-film transistors," J. Non-Cryst. Solids, vol. 354, no. 19-25, pp. 2826-2830, May 2008.

[61] Y. Jeong, C. Bae, D. Kim, K. Song, K. Woo, H. Shin, G. Cao, and J. Moon, "Bias-stress-stable solution-processed oxide thin film transistors," ACS Appl. Mater. Interfaces, vol. 2, no. 3, pp. 611-615, Mar. 2010.

[62] T. H. Ning and H. N. Yu, "Optically induced injection of hot electrons into $\mathrm{SiO}_{2}$," J. Appl. Phys., vol. 45, no. 12, pp. 5373-5378, Dec. 1974.

[63] F. R. Libsch and J. Kanicki, "Bias-stress-induced stretched-exponential time dependence of charge injection and trapping in amorphous thin-film transistors," Appl. Phys. Lett., vol. 62, no. 11, pp. 1286-1288, Mar. 1993.

[64] S. Zafar, A. Callegari, E. Gusev, and M. V. Fischetti, "Charge trapping related threshold voltage instabilities in high permittivity gate dielectric stacks," J. Appl. Phys., vol. 93, no. 11, pp. 9298-9303, Jun. 2003.

[65] J. K. Jeong, H. W. Yang, J. H. Jeong, Y. G. Mo, and H. D. Kim, "Origin of threshold voltage instability in indium-gallium-zinc oxide thin film transistors," Appl. Phys. Lett., vol. 93, no. 12, p. 123 508, Sep. 2008.

[66] K. T. Kim, K. Lee, M. S. Oh, and S. Im, "Surface induced time dependent instability of $\mathrm{ZnO}$ based thin film transistors," Thin Solid Films, vol. 517, no. 23 , pp. $6345-6348$, Oct. 2009.

[67] J. S. Park, J. K. Jeong, H. J. Chung, Y. G. Mo, and H. D. Kim, "Electronic transport properties of amorphous indium-gallium-zinc oxide semiconductor upon exposure to water," Appl. Phys. Lett., vol. 92, no. 7, p. 072 104, Feb. 2008.

[68] D. Hong and J. F. Wager, "Passivation of zinc-tin-oxide thin film transistors," J. Vac. Sci. Technol. B, Microelectron. Nanometer Struct., vol. 23, no. 6, pp. L25-L27, Nov. 2005.

[69] D. Kang, H. Lim, C. Kim, I. Song, J. Park, Y. Park, and J. G. Chung, "Amorphous gallium indium zinc oxide thin film transistors: Sensitive to oxygen molecules," Appl. Phys. Lett., vol. 90, no. 19, p. 192101 , May 2007.

[70] P. Gorrn, T. Riedl, and W. Kowalsky, "Encapsulation of zinc tin oxide based thin film transistors," J. Phys. Chem. C, vol. 113, no. 25, pp. 11 12611 130, Jun. 2009

[71] Y. Ye, R. Lim, and J. M. White, "High mobility amorphous zinc oxynitride semiconductor material for thin film transistors," J. Appl. Phys., vol. 106, no. 7, p. 074512 , Oct. 2009.

[72] C. C. Huang, B. Pelatt, and J. F. Conley, Jr., "Directed integration of $\mathrm{ZnO}$ nanobridge sensors using pre-patterned carbonized photoresist," Nanotechnology, vol. 21, no. 19, p. 195 307, May 2010.

[73] W. Kim and K. S. Chu, "ZnO nanowire field-effect transistor as a UV photodetector; optimization for maximum sensitivity," Phys. Stat. Sol. (A), vol. 206, no. 1, pp. 179-182, Jan. 2009

[74] D. H. Levy, D. Freeman, S. F. Nelson, P. J. Cowdery-Corvan, and L. M. Irving, "Stable $\mathrm{ZnO}$ thin film transistors by fast open air atomic layer deposition," Appl. Phys. Lett., vol. 92, no. 19, p. 192 101, May 2008.

[75] D.-H. Cho, S. Yang, C. Byun, J. Shin, M. K. Ryu, S.-H. K. Park, C.-S. Hwang, S. M. Chung, W.-S. Cheong, S. M. Yoon, and H.-Y. Chu, "Transparent $\mathrm{Al}-\mathrm{Zn}-\mathrm{Sn}-\mathrm{O}$ thin film transistors prepared at low temperature," Appl. Phys. Lett., vol. 93, no. 14, p. 142 111, Oct. 2008.
[76] D.-H. Cho, S. Yang, S.-H. Ko Park, C. Byun, S.-M. Yoon, J.-I. Lee, C.-S. Hwang, H. Y. Chu, and K. I. Cho, "21.2: Al and Sn doped zinc indium oxide thin film transistors for AMOLED back-plane," in Proc. SID, 2009, pp. 280-283.

[77] S. K. Park, Y. H. Kim, H. S. Kim, and J. I. Han, "High performance solution-processed and lithographically patterned zinc-tin oxide thin-film transistors with good operational stability," Electrochem. Solid-State Lett., vol. 12, no. 7, pp. H256-H258, 2009.

[78] D. H. Levy, S. F. Nelson, and D. Freeman, "Oxide electronics by spatial atomic layer deposition," J. Display Technol., vol. 5, no. 12, pp. 484-494, Dec. 2009.

[79] P. M. Lenahan and J. F. Conley, Jr., "What can electron paramagnetic resonance tell us about the $\mathrm{Si} / \mathrm{SiO}_{2}$ system?" J. Vac. Sci. Technol. B, Microelectron. Nanometer Struct., 16, no. 4, pp. 2134-2153, Jul. 1998.

[80] J. F. Conley, Jr., "Application of electron spin resonance as a tool for building in reliability," in Materials Reliability in Microelectronics VI, W. F. Filter, J. J. Clement, A. S. Oates, R. Rosenberg, and P. M. Lenahan, Eds. Pittsburgh, PA: Mater. Res. Soc., 1996, pp. 293-315.

[81] J. F. Conley, Jr. and P. M. Lenahan, "A review of electron spin resonance spectroscopy of defects in thin film $\mathrm{SiO}_{2}$ on $\mathrm{Si}$," in The Physics and Chemistry of $\mathrm{SiO}_{2}$ and the $\mathrm{Si} / \mathrm{SiO}_{2}$ Interface 3, H. Z. Massoud, E. H. Poindexter, and C. R. Helms, Eds. Pennington, NJ: ECS, 1996, pp. 214-249.

[82] P. C. Taylor, Semiconductors and Semi-Metals, J. I. Pancove, Ed. New York: Academic, 1984, p. 99.

[83] J. T. Krick, P. M. Lenahan, and J. Kanicki, "Electrically active pointdefects in amorphous-silicon nitride-An illumination and charge injection study," J. Appl. Phys., vol. 64, no. 7, pp. 3558-3563, Oct. 1988.

[84] P. M. Lenahan and J. F. Conley, Jr., "Magnetic resonance studies of trapping centers in high- $\kappa$ dielectric films on silicon," IEEE Trans. Device Mater. Rel., vol. 5, no. 1, pp. 90-102, Mar. 2005.

[85] K. Vanheusden, W. L. Warren, C. H. Seager, D. R. Tallant, J. A. Voigt, and B. E. Gnade, "Mechanisms behind green photoluminescence in $\mathrm{ZnO}$ phosphor powders," J. Appl. Phys., vol. 79, no. 10, pp. 7983-7990, May 1996.

[86] M. Kimura, T. Nakanishi, K. Nomura, T. Kamiya, and H. Hosono, "Trap densities in amorphous- $\mathrm{InGaZnO}_{4}$ thin-film transistors," Appl. Phys. Lett., vol. 92, no. 13, p. 133512 , Mar. 2008.

[87] H. H. Hsieh, T. Kamiya, K. Nomura, H. Hosono, and C. C. Wu, "Modeling of amorphous $\mathrm{InGaZnO}_{4}$ thin film transistors and their subgap density of states," Appl. Phys. Lett., vol. 92, no. 13, p. 133 503, Mar. 2008.

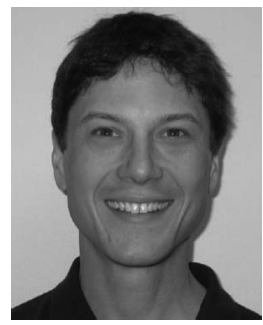

John F. Conley, Jr. (M'92-SM'02) received the B.S. degree in electrical engineering and the Ph.D. degree in engineering science and mechanics from The Pennsylvania State University, University Park, in 1991 and 1995, respectively.

He was with the Dynamics Research Corporation from 1995 to 2000 and with the Jet Propulsion Laboratory from 2000 to 2001, where he received an achievement award. In 2001, he became a Senior Member of the technical staff at Sharp Laboratories of America, and from 2005 to 2007, he was the Leader of the Novel Materials and Devices Group. In 2002-2003, he served as an Adjunct Professor with the Washington State University, Vancouver. Since 2007, he has been a Professor and an ONAMI Signature Faculty Fellow with the Oregon State University, Corvallis, both in the School of Electrical Engineering and Computer Science and the Intercollege Materials Science Program. He has authored or coauthored over 100 technical papers (including several invited) and over 100 conference presentations. He is the holder of 18 U.S. patents. $\mathrm{He}$ has presented tutorial short courses on high- $\kappa$ dielectrics at two international conferences. His research interests include atomic layer deposition, high- $\kappa$ dielectrics, thin-film transistors, metal/insulator/metal tunnel diodes, directed integration of nanomaterials and nanodevices, and point defects, reliability, and radiation effects in novel electronic materials.

Dr. Conley has served on the technical and management committees of the IEEE IRPS, the IEEE SOI Conference, and the IEEE Nuclear and Space Radiation Effects Conference. He was the Technical Program Chair of the 2000 IEEE Microelectronics Reliability and Qualification Workshop and the General Program Chair of the 2006 IEEE International Integrated Reliability Workshop. He won a 1996 Xerox Prize for his Ph.D. dissertation. He has served as a Guest Editor for three special issues of the IEEE TRANSACTIONS ON DEVICE AND Materials Reliability. 